\title{
Upgrade of a climate service tailored to water reservoirs management
}

\author{
E. Sánchez-García ${ }^{\text {a, }}$, I. Abia ${ }^{\text {a }}$, M. Domínguez ${ }^{\text {a }}$, J. Voces ${ }^{\text {a }}$, J.C. Sánchez ${ }^{\text {a }}$, B. Navascués ${ }^{\text {a }}$, \\ E. Rodríguez-Camino ${ }^{a}$, M.N. Garrido ${ }^{a}$, M.C. García ${ }^{b}$, F. Pastor ${ }^{b}$, M. Dimas ${ }^{c}$, L. Barranco $^{c}$, \\ C. Ruiz Del Portal ${ }^{\mathrm{d}}$
}

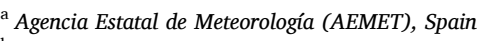

${ }^{\mathrm{b}}$ Dirección General del Agua (D.G. Water), Spain

${ }^{\mathrm{c}}$ Centro de Estudios Hidrográficos - CEDEX, Spain

d Confederación Hidrográfica del Miño-Sil, Spain
}

\section{A R T I C L E I N F O}

\section{Keywords:}

Reservoir management

Hydrological hazard

Seasonal prediction

Climate service

NAO

Web tool

\begin{abstract}
A B S T R A C T
We present the upgrade of a web tool designed to help in the decision making process for water reservoirs management in Spain. The tool, called S-ClimWaRe (Seasonal Climate predictions in support of Water Reservoirs management), covers the extended winter season (from November to March), when the North Atlantic Oscillation (NAO) pattern strongly influences the hydrological interannual variability in South-Western Europe. This climate service is fully user driven, and aims at meeting their requirements incorporating recent scientific progress.

The latest S-ClimWaRe version includes some technical enhancements requested by customers and new seasonal predictions obtained through application of two postprocessing steps to ECMWF System- 5 forecasts: a downscaling statistical procedure, and a new methodology that improves the forecast skill of hydrological variables through an enhanced prediction of the winter NAO. The new version enriches the forecasting panel of the web tool with precipitation forecast skill, and provides additional forecasts for accumulated snowfall and temperature. Water reservoir inflow forecasts are generated by a hybrid statistical system and are also skilful in areas influenced by the NAO pattern. In regions not directly affected by this climate driver, a revision of this simple impact model seems to be needed. A prototype based on two different hydrological models has been tested over a pilot reservoir. The assessment of this downscaling procedure shows promising results with respect to the existing seasonal forecasts based on the statistical approach relying on the predicted NAO index.
\end{abstract}

Practical implications

Water management in Spain needs to deal with the high spatial and temporal variability of precipitation. This variability leads to the need to be able to satisfy water demands under drought conditions, keeping in mind the efficient use of water resources taking into account its quality and quantity, as well as managing flood events. For doing so, water Planning aims to reach good status of water bodies, to protect Public Water Domain, to satisfy water demands, to increase water resources availability and to cope with flood risk.

Annual mean runoff in Spain is around $111.000 \mathrm{hm} 3 /$ year, meanwhile natural water flows available are around $9.000 \mathrm{hm} 3$, not enough to deal with actual water demand with an estimate of $35.000 \mathrm{hm} 3 /$ year (MIMAM, 2000). The gap between available natural resources and water demand is the main driver for water infrastructure such as desalination plants, reusing water facilities and reservoirs. Nowadays there are over 1500 reservoirs in Spain

Abbreviations: EQENSM, Postprocessing strategy of forecasts by the different ensemble members that considers them as equiprobable; SEAS5, ECMWF System-5 seasonal forecasting system; SEAS5-D, Downscaling of ECMWF System-5 seasonal forecasting system; S-ClimWaRe, Seasonal Climate predictions in support of Water Reservoirs management. The acronym is used both to call the climate service, and the statistically based seasonal forecasting system for precipitation and water inflow initially implemented; S-ClimWaRe-H, Hybrid method to obtain seasonal forecasts of water inflow that is based on the usage of the NAO index obtained by combination of different seasonal forecasting systems within the statistical system initially developed; WENSM, Postprocessing strategy of forecasts by the different ensemble members that assigns them a different weight according to the ECMWF System-5 NAO index forecast of each member.

* Corresponding author.

E-mail address: esanchezg@aemet.es (E. Sánchez-García). 


\section{(MITERD, 2021).}

The added value of seasonal forecast in the water sector has been recognised in different papers and there is an increased trend in the use of seasonal forecast for reservoir operations (Guihan et al., 2014; Visser, 2017; Long et al., 2019).

The S-ClimWare (Seasonal climate predictions in support of Water reservoirs management) project and its outcomes have been developed with the aim to be an instrument for supporting water managers in their decision-making process. Since 2014, a cycle of regular interaction between the Spanish D.G. Water and AEMET has allowed progress on the development and delivering of a continuously enhanced climate service. Over this time, private companies and other academic institutions have taken part in the project, suggesting methods or study cases on water allocation schemes based on probabilistic forecasts of water inflow in certain reservoirs (Pouget et al., 2015). More recently, CEDEX, the governmental institution in charge of the evaluation of water resources for D.G. Water, has also joined S-ClimWaRe to provide hydrological simulations over a pilot river basin within the latest climate service prototype development.

Apart from the main achievement of the S-ClimWaRe project, that is building a cooperation platform among Meteorological and Hydrological administrations with regular interactions and knowledge sharing, the web viewer recently opened to the general public (see https://www.miteco.gob.es/es/agua/temas/ evaluacion-de-los-recursos-hidricos/Prediccion-estacionalgestion-embalses.aspx and http://www.aemet.es/es/serviciosclimaticos/apoyo_gestion_embalses) is a tool with multiple potential applications and benefits. Several diagnostics based on historical observations of hydrological variables and seasonal predictions presented at the web tool cover 388 reservoirs that account $95 \%$ of the total storage capacity of the reservoirs in Spain, which updated information is regularly published at the DGA web site (http://eportal.miteco.gob.es/BoleHWeb/). Forecasts for water inflow, precipitation, snowfall and temperature for the extended winter November to March period suits the needs that have been previously agreed with water managers from different river basin districts.

The potential and current practical implications of the information provided by the S-ClimWaRe web tool listed by water managers comprises: improving water allocation schemes (irrigation, hydroelectric, domestic uses), flow regulation, agreeing environmental flows, being an input for the Commission for Dam Releases, planning during drought events: establishing dam releases as well as minimum flows, improving decision making during flood events, planning hydroelectric power production, setting up Operating Rules for the Reservoir or as an input in River Basin Management Plans, for example.

In addition, multiple stakeholders could also benefit from including the seasonal forecasts provided by the web tool in the decision-making process, such as Irrigation Commissions, Water Consumer Boards, Urban Water Consortiums and Hydroelectric companies.

Although the usage of this climate service is still incipient within water reservoirs management in Spain, a progressive uptake of this information is expected in coming years. The development of practical cases of usage and the exchange of experiences will favour it.

\section{Introduction}

Winter precipitation presents a high inter-annual variability in areas of Southwestern Europe (Rodríguez-Puebla et al., 1998). This has led to the existence of over 1500 reservoirs that -jointly with ground water storages, some desalination plants and other infrastructures- are used in Spain to ensure public water supply, satisfy irrigation needs, produce hydroelectricity, support some industrial activities and sports, laminate floods, and keep environmental flows. The River Basin Authorities, coordinated by the Spanish D. G. Water (Ministry for the Ecological Transition and the Demographic Challenge), are in charge of the management of the largest reservoirs.

Within the activities of implementation in Spain of the Global Framework for Climate Services (Hewitt et al., 2012), in spring 2014 a workshop on the use of seasonal climate predictions for improving water management was held at the headquarters of the State Meteorological Agency of Spain (AEMET). The event was co-organized by the EUPORIAS project (EU 7th Framework Program, see https://cordis.europa. eu/project/id/308291), whose purpose was to demonstrate the benefits of incorporating information and seasonal climate predictions in decision making processes through systems for predicting climate impacts in different sectors (Buontempo et al., 2018). Following the actions recommended in this workshop, a partnership between the D. G. Water and AEMET emerged to develop a fully user driven case study called SClimWaRe (Seasonal Climate predictions in support of Water Reservoirs Management in Spain). The strong engagement of the project stakeholders, even after the EUPORIAS lifetime, has allowed to deliver a periodically improved S-ClimWaRe climate service.

Predictability at seasonal time scale of hydrological variables, such as streamflow or reservoir inflow, comes from two components of the Earth system, the initial hydrological conditions (e.g. snowpack, soil moisture, streamflow, water reservoir levels...), and/or from the oceanic and atmospheric large scale patterns that may strongly influence climate variability at the target region (Arnal et al., 2018), as it is the case of El Niño-Southern Oscillation (ENSO) at Pacific surrounding regions, or the North Atlantic Oscillation (NAO) in winter over Southwestern Europe. In areas and seasons where this last factor dominates, the limited skill of seasonal forecasts produced by the Global Circulation Models (GCM) hampers the development of climate services based on them that are useful for end users, or reduces their lead time. Over Europe, the skill of seasonal forecasts is low (Doblas-Reyes, 2012), and this has been an issue for meeting specific user's needs. Arnal et al. (2018) have reported that probabilistic forecasts of streamflow produced at pan-European scale by the Copernicus climate service EFAS (European Flood Awareness System) are, on average, less skilful than those produced by the same hydrological model forced by an ensemble of historical meteorological observations for lead times longer than 1 month. Olsson et al. (2016) also show that only early forecasts outperform time series of temperature and precipitation from historical years as meteorological forcing to predict spring flood in Sweden. Grillakis et al. (2018) find that seasonal forecasts by two different state-of-the-art GCMs used to drive the same hydrological model provide skilful streamflow predictions on a water resource watershed on the island of Crete for one month ahead, with the skill decreasing rapidly beyond this time horizon. However, the assessment of the EUPORIAS prototype RIFF (River flow forecast over France), using late spring-summer seasonal forecasts for improving decision making at a specific reservoir, was promising (Viel et al., 2016).

One of the first requirements of S-ClimWaRe stakeholders was to dispose of anticipated accumulated water inflow estimates during the filling reservoir period (November to March). Although the initial case study focused on a few pilot reservoirs, the scope was afterwards extended to any reservoir in the Spanish territory, and a web based tool was developed and implemented operationally (Voces et al., 2019). Provided the influence of NAO as a climate driver in this region and season, the approach adopted by S-ClimWaRe was the one suggested by the International Research Institute for Climate and Society (IRI) and carried out in other countries such as Philippines and United States (Brown et al., 2010), whose climate variability seasonal scale is highly conditioned by ENSO. Following this approach, the S-ClimWaRe website was organized in two main displaying panels. The first one allows the user to explore, for any water reservoir or grid point over continental Spain, the existing hydrological variability and hazard linked to climate variability. This is performed through a set of indicators obtained from time series of hydrological and meteorological observations and NAO 
index. The second displaying panel of the web tool supplies seasonal predictions for November to March accumulated water reservoir inflow and precipitation. When the S-ClimWaRe project began, some global GCMs started to show remarkable skill to predict the winter NAO (e.g., Riddle et al. 2013; Scaife et al. 2014, and Stockdale et al. 2015). However the predicted NAO signal is rather weak, making precipitation seasonal forecasts over Spain unskilful (Sánchez-García et al., 2014). For this reason, the seasonal forecasts initially implemented in the S-ClimWaRe viewer came from an empirical forecasting system (Voces et al., 2016; Voces et al., 2019), based on the autumn boreal snow cover advance as a predictability source for the winter NAO (Cohen and Jones, 2011). The skill of these statistical forecasts for winter precipitation and water inflow were shown to be notable over wide Spanish regions influenced by this climate driver. Probabilistic forecasts and its skill were jointly displayed in the web tool. This tool was originally flexible designed with respect to sources of seasonal forecasts and extension to additional climate drivers, variables and seasons. In this way, user requirements and scientific progress could be easily incorporated into new versions of this climate service.

The main goal of climate services is to achieve better climate risk management through the incorporation of science-based climate information and prediction in decision-making processes. Thus, they usually rely on the appropriate application of already existing scientific results and data for the pursued purposes. Once the first version of S-ClimWaRe web tool was operational, the cycle of regular interaction with stakeholders of this climate service led to new user's requirements for the extended winter season. Scientific and technical progress has made possible enhanced and new seasonal forecasts for all these variables. In this paper, we present the latest version of the S-ClimWaRe web tool improving the previous one described by Voces et al. (2019). Open access to this tool has been made through both AEMET and D.G. Water websites (http://www.aemet.es/es/serviciosclimaticos and htt ps://www.miteco.gob.es/es/agua/temas/evaluacion-de-los-recursos-h idricos/Prediccion-estacional-gestion-embalses.aspx). The climate service upgrade has been co-designed with its users to meet their requirements. Technical enhancements have been introduced to satisfy some of them. This paper gives some information about the stakeholder's interaction, but more details about it can be found in Rodriguez et al. (submitted). On the other hand, improvements in seasonal forecasts have been achieved making use of new data, and novel methods that rely on already existing and documented basic approaches but had not yet been applied for variables like water inflow or snowfall, or had not been successively used for precipitation. This paper is mostly devoted to show these novel developments implemented and the added value of each of them.

The document is structured as follows: Section 2 shortly presents the co-design and goals of this climate service update, Section 3 describes the data and methods applied in the latest enhancement of the web tool; its assessment and a discussion of the results obtained are presented in Section 4; and Section 5 concludes with a summary and final remarks.

\section{Co-design and goals of the climate service update}

The S-ClimWaRe web tool is a user driven climate service that is sustained by a regular cycle of interaction with stakeholders. This cycle begins with periodic surveys and workshops jointly organised by D.G. Water and AEMET to collect user's requirements that are then examined along with the latest scientific or technical advances and available data that might help to meet them. This step is followed by the co-design of a new version of the tool, the joint monitoring of the on-going developments, and the cooperative assessment of the corresponding prototype. A multidisciplinary team, that includes members from both the users and providers sides, is established for these purposes. The different tasks to be carried out are then allocated and scheduled in a Work Plan that is regularly monitored. Final users of the climate service from River Basin Authorities and D.G. Water representatives mainly contribute by providing datasets and specific requirements, including those concerning the impact model -intended to translate climate forcing into hydrological variables- to be used. They also actively participate in the subjective assessment of the evolving prototypes and by proposing practical cases of usage. Sometimes, but not always, these developments have been also framed in $\mathrm{R}+\mathrm{D}+\mathrm{I}$ Projects funded by the EU. The cyclic process is completed with the necessary training on content and usage of the new developed climate service.

Once the preliminary S-ClimWare web tool described in Voces et al. (2019) was implemented, the regular cycle of interaction with stakeholders gave place to the revision and subsequent upgrade of the forecasting panel of this climate service that is described in this paper. The new set of enhancements agreed, co-designed and jointly assessed by users and providers responded to the following goals:

- Better customize the information presented at the climate service.

- Take advantage of observational grids, reanalysis and seasonal forecasts made freely available by the Climate Change service of the European Copernicus program (https://climate.copernicus.eu/).

- Improve the skill of the current forecasts for winter precipitation, based on an empirical method, while keeping a high spatial resolution.

- Provide seasonal forecasts for two additional variables: accumulated snowfall and mean temperature for the extended winter period.

- Test at a pilot water reservoir the potential of a downscaling method based on the usage of hydrological models to produce seasonal forecasts for water inflow that are consistent with those for precipitation and snowfall.

The next section describes data and methods applied to reach these objectives as their comparison to similar strategies documented in the literature. An additional institution, CEDEX, has joined D.G. Water and AEMET to achieve the last goal listed above. The new version of the web tool has been developed in the framework of the MEDSCOPE project (MEDiterranean Services Chain based On climate PrEdictions, htt ps://www.medscope-project.eu/) within the initiative ERA4CS (European Research Area for Climate Services, http://www.jpi-climate. eu/ERA4CS). All these enhancements are part of demonstration prototypes developed during the project and make use of functions integrated in the MEDSCOPE Climate Services Toolbox (CSTools).

\section{Data and methods}

Data

The original version of S-ClimWaRe web tool is based on different hydrological, meteorological and climate free access sources of information, in addition to baseline geographical datasets:

- Historical monthly data of reservoir inflow and dammed water from the Gauges Yearbook maintained by D.G. Water (https://www.mi teco.gob.es/en/cartografia-y-sig/ide/descargas/agua/anuario-de-af oros.aspx). The Gauges Yearbook is the official registry of hydrological data in Spain. It gathers the validated hydrometric data from the Hydrological Control Networks (SAIH-ROEA) operated by the River Basin Authorities, serving as a reference for the knowledge of the amount of water in rivers, reservoirs, and pipelines throughout the national territory.

- Daily precipitation and temperature gridded data at $5 \mathrm{~km}$ resolution (from 1951 onwards) provided by AEMET have been used as meteorological observations (http://www.aemet.es/es/serviciosclimat icos/cambio_climat/datos_diarios? $w=2$ ). This gridded dataset covering the Spanish domain is based on observations from the high resolution climate station network operated by AEMET (Peral et al., 2017; Amblar-Francés et al., 2020). 
- Historical data of Northern Hemisphere snow coverage from the Interactive Multisensor Snow and Ice Mapping System analysis of the U.S. National Snow and Ice Data Center (IMS, Helfrich et al., 2007). This daily product is derived from visible and microwave satellite imagery (https://nsidc.org/data/g02156).

- Time series of the standardized NAO index data published by the National Oceanic and Atmospheric Administration (NOAA) (https:// www.cpc.ncep.noaa.gov/products/precip/CWlink/pna/nao.shtml).

The adoption of seasonal forecasts produced by GCMs has been a major step forward. With it, the second goal formulated to enhance the climate service is also met. The upgraded climate service makes additionally use of these datasets:

- The ECMWF ERA-Interim (ERAI, Dee et al., 2011) reanalysis dataset (https://www.ecmwf.int/en/forecasts/datasets/reanalysis-datase ts/era-interim)

- The Copernicus ERA-5 reanalysis dataset (Hersbach et al., 2019) at $0,25^{\circ} \times 0,25^{\circ}$ resolution (https://cds.climate.copernicus.eu/cdsa $\mathrm{pp} \#$ !/dataset/reanalysis-era5-single-levels-monthly-means-prelimi nary-back-extension?tab=overview)

- Seasonal forecasts from the ECMWF System-5 seasonal forecasting system (SEAS5), available at the Copernicus climate data store (http s://cds.climate.copernicus.eu)

- Shapefiles of river catchments and snowpack basins provided by D.G. Water (https://www.miteco.gob.es/es/cartografia-y-sig/ide/desca rgas/agua/default.aspx)

All these data are processed as described in the following section to feed the S-ClimWaRe web tool. Apart from the data listed above, other datasets have been also used for different purposes in the work shown in this paper:

- The E-OBSv16 daily gridded meteorological data for Europe (KleinTank et al., 2002) at $0.5^{\circ} \times 0.5^{\circ}$ resolution available at the Copernicus climate data store (https://cds.climate.copernicus.eu/cds app\#!/dataset/insitu-gridded-observations-europe?tab=overview). This dataset is derived from a lower density of in situ observations network than the used within the web tool and has been employed for the assessment of GCMs seasonal forecasts of temperature and precipitation.

- The physiographic databases used by SIMPA and SURFEX hydrological models employed to simulate water inflow at the pilot Belesar reservoir: CORINE Land Cover 2000, Lithostratigraphy, Permeability and Hydrogeological map of Spain of the Geological and Mining Institute, 1:200.000, Soil Map of the European Communities, 1:1.000.000, Spanish Soil Database (CIEMAT-CSIC) and Digital Terrain Model of the Spanish National Geographic Institute, for SIMPA model, and Ecoclimap-II for Europe for SURFEX (Masson et al, 2003).

\section{Methods}

\section{Customization of the S-ClimWare web tool}

One goal of the S-ClimWare update was to reach a better customization in order to ensure a useful climate service. In accordance with the requests expressed by users in the periodic surveys carried out, the working group, including both users and providers, in charge of designing the web tool update have put a special emphasis on enabling the understanding of two key features of seasonal forecasts: uncertainty and reliability. The probabilistic nature of seasonal climate forecasts, that impacts the predictions of water inflow, makes their uptake and usage difficult. Communication of the forecast uncertainty is a challenge that has required the joint work of the stakeholders in order to find the best solution to represent it. Besides, the tool provides the forecast skill, a key feature for improving the decision-making process (Turner et al.,
2017). The skill is a guidance of the estimated quality of the forecast that provides essential information on its reliability and has an impact on the user's confidence in the predictions. As a matter of fact, skill is one of the main factors pointed out by users as very useful or determinant for implementing, or not, the forecast in their daily work, including deciding water allocation, planning for extreme events (floods and droughts), and improving irrigation schemes and hydroelectric operations.

Transparency levels, colours, different plot types and masking procedures have been agreed and applied to better represent these two features of seasonal forecasts. These enhancements are complemented with new and specific panels for seasonal forecasts of November to March mean temperature and accumulated snowfall. In addition, some changes concerning new indicators and functionalities have been implemented to satisfy the list of requirements prepared by users. The results are presented in a later section of this document.

Postprocessing of ECMWF seasonal forecasts based on MEDSCOPE CSTools

Two functions from the MEDSCOPE CSTools (Pérez-Zanón et al., 2021) have allowed to improve the precipitation forecast skill, as stated at the objectives of the web tool update. They are successively applied to postprocess SEAS5 forecasts and are based on already existing basic approaches. However, they had not been used jointly for precipitation. For other hydrological variables, like snowfall or water inflow, they had never been tried before.

The first CSTools function is an analogs based method that had been used as a regionalization technique for climate change projections in this area (Amblar-Francés et al., 2020). This downscaling method is applied in this work to SEAS5 ensemble members on a daily basis to produce an ensemble of precipitation forecasts at $5 \mathrm{~km}$ resolution. Earlier trials to downscale dynamically ECMWF System-3 seasonal precipitation forecasts to $0.5^{\circ} \times 0.5^{\circ}$ resolution over the same region (Díez et al., 2011) had limited success due to the skill of this GCM version at mid-latitudes.

The second function from CSTools employed in this climate service is a new approach developed by Sánchez-García et al. (2019) called Best NAO estimation. It aims at improving the skill of the available seasonal forecasts for this geographical area through a better prediction of the NAO state in the coming winter. This technique first corrects the systematically low signal of the predicted NAO by the ECMWF System- 5 Seasonal Forecasting System (SEAS5). Stringer et al. (2020) have also developed a method to adjust the currently underestimated NAO signal predicted by the UKMO GloSea5 Seasonal Forecasting System (SFS). This CSTools function then combines the calibrated SEAS5 NAO index with other skilful winter NAO index estimates to weight the forecasts of the SEAS5 ensemble members. Sánchez-García et al. (2019) have demonstrated the enhancement of the SEAS5 forecast skill for NAO index and precipitation over Spain in winter using the Best NAO approach. In this work, we show the impact of this method on the skill of seasonal forecasts for November to March accumulated SEAS5 downscaled precipitation.

Seasonal forecasts for mean near surface temperature at high resolution are achieved through application of the CSTools analogs method for this variable to downscale SEAS5 ensemble members at $5 \mathrm{~km}$ resolution. In case of snowfall, the Best NAO estimation function is for the first time applied to SEAS5 ensemble members.

The methodology employed to postprocess SEAS5 forecasts consisting in the application of two functions from the MEDSCOPE CSTools package is described in more detail hereafter. It is applied not only to the current year forecast, but also over the 1997-2016 hindcast period, as seasonal forecasts for the past years and their skill are part of the information offered by the web tool. The methodology employed to obtain the forecast skill is presented in the assessment section of this document.

Statistical downscaling of SEAS5 seasonal forecasts. AEMET has contributed to the MEDSCOPE CSTools package with an analogs procedure 
(Petisco de Lara, 2008a, b; Hernanz et al., 2021) for downscaling of seasonal forecasts for precipitation and daily extreme temperatures. This method has been applied to SEAS5, originally at around $35 \mathrm{~km}$ resolution, to obtain an ensemble of seasonal forecasts for these three variables on the $5 \mathrm{~km}$ resolution grid used by the web tool. We call this downscaled seasonal forecast SEAS-D.

The AEMET analogs downscaling method is applied to derive precipitation or maximum/minimum temperature at finer resolution from the coarser spatial resolution SEAS5 data through the association with an observational high resolution dataset and a collection of predictors (local analogy) and reference synoptic situations, similar to the estimated day. We have used reanalysis data from ERAInterim to characterize the synoptic situations in a reference period (1981-2006), the observational high resolution dataset from AEMET and the large-scale atmospheric circulation simulated by SEAS5. As predictors, for precipitation we have used mean sea level pressure, thermal vertical gradient between $500 \mathrm{hPa}$ and $850 \mathrm{hPa}$, temperature in different levels (500/850 $\mathrm{hPa}$ ), vorticity, geostrophic wind at sea level and specific humidity at $700 \mathrm{hPa}$. For maximum/minimum temperature, temperature at different levels $(500 / 700 / 850 \mathrm{hPa}), 2 \mathrm{~m}$ temperature, insolation and specific humidity at $700 \mathrm{hPa}$ have been used.

The large-scale atmospheric circulation, is compared to each of the atmospheric configurations in the reference period and a group of the $N$ most similar days, defined by the Euclidean distance of the selected variables $(\mathrm{u} / \mathrm{v}$ geostrophic wind components and $\mathrm{u} / \mathrm{v}$ wind components at $500 \mathrm{hPa}$, weighted according to the distance to the target region), are chosen as their analogs. For maximum/minimum temperature, the most analog days to the estimated day are searched. Then, for each grid point, a multiple linear regression is applied with all predictors from the analog days. The precipitation is calculated as a weighted average of a selection of analog days, with weights depending on their analogy. In addition, the local analogy observed in the chosen analog days (as the Euclidean distance of significant predictors), is associated with the simulated model large-scale pattern and used in combination with synoptic analogy, to downscale the precipitation.

Seasonal forecasts for accumulated snowfall are presented at the SEAS5 resolution $\left(0.25^{\circ} \times 0.25^{\circ}\right.$ lat-lon $)$, because a simple downscaling for this variable at a reduced computational cost has not been addressed yet. In case of water inflow seasonal forecasts, those produced by the statistical system are already local. However, the prototype for the Belesar reservoir described in the following methods subsection makes use of these SEAS-D downscaled precipitation and temperature fields as part of the meteorological forcing to drive the two hydrological models employed.

Combination of different NAO index information sources to enhance the skill of precipitation and snowfall forecasts. The second function employed from MEDSCOPE CSTools is the Best NAO algorithm that combines different skilful DJF NAO index forecasts to obtain an optimal NAO pdf that is used to weight ensemble members forecasts (Sánchez-García et al., 2019). This method has been applied to obtain seasonal forecasts of precipitation, snowfall and water inflow. At least two different seasonal forecast systems that have shown to be skilful in predicting the winter NAO index are selected. One of them comes from the statistical system initially implemented, that relies on the snow cover advance in the boreal autumn (calculated using the IMS snow product) and DJF NAO teleconnection (Voces et al., 2016). The second one is the ensemble mean of DJF NAO forecasts predicted by the SEAS5 ensemble members. ERA-Interim reanalysis and Copernicus SEAS5 seasonal forecasts are used to calculate time series of observations and seasonal forecasts for DJF NAO index (see Sánchez-García et al., 2019 for details about NAO index computation). As in Riddle et al. (2013), we have evaluated here separately the skill of seasonal forecasts for the different lead times, and that of a superensemble based on ensemble members from different forecast starting dates (see Table 1). We have found that the highest
Table 1

Correlation coefficient between DJF NAO index obtained with ERA-Interim reanalysis and the ensemble mean of NAO index for different lead time seasonal forecasts. The correlation coefficients reached by a superensemble based on SEAS5 forecasts with two different lead times (before and after bias correction), and that obtained by S-ClimWaRe statistical method, are also included. Verification period: 1997-2015.

\begin{tabular}{lll}
\hline Source of NAO index forecast & Forecast starting date & $\begin{array}{l}\text { R (Correlation } \\
\text { coefficient) }\end{array}$ \\
\hline SEAS5 & 1st September & 0.53 \\
SEAS5 & 1st October & 0.43 \\
SEAS5 & 1st September + 1st & 0.59 \\
& October & \\
Bias corrected SEAS5 & 1st September + 1st & 0.64 \\
& October & \\
S-ClimWaRe & - & 0.32 \\
Bias corrected SEAS5 + S- & - & 0.65 \\
$\quad$ ClimWaRe & & \\
\hline
\end{tabular}

correlation with the observed NAO is reached when a 50 members' superensemble including forecasts starting in September and October is used. Once the estimates of the winter NAO are selected, the approach described in Sánchez-García et al. (2019) is applied. It starts by correcting the bias of the NAO signal forecasted by SEAS5. Table 1 shows that this procedure produces an increased correlation of the adjusted SEAS5 superensemble mean of NAO index with ERA-Interim derived observations. The CSTools also characterises the errors of the two selected estimates. Then, a Gaussian Best NAO pdf is obtained using a statistical linear estimation algorithm that takes into account the errors characteristics of the two previous estimates, and provides the optimal NAO index and its accuracy. As it can be seen in Table 1, this Best NAO index correlates the most with ERA-Interim derived observations. This NAO pdf is finally used to weight the ensemble members' forecasts depending on their respective predicted NAO index. Along this work, we call WENSM to this ensemble forecasts postprocessing strategy that relies on the Best NAO estimate forecasted for the coming winter. The one considering ensemble member's forecasts as equiprobable, consistent with the winter NAO predicted by SEAS5, is named EQENSM strategy.

Testing the usage of hydrological models and MEDSCOPE CSTools to produce winter inflow forecast at the pilot Belesar water reservoir

With respect to the improvement of seasonal forecasts of water inflow, another potential enhancement has been tested to meet the last goal of the S-ClimWaRe update listed at Section 2. Two hydrological models have been run to produce probabilistic forecasts of water inflow into a pilot reservoir, the Belesar reservoir. They are the SIMPA hydrological model (CEDEX, 2020), and the offline SURFEX land surface model (Masson et al., 2013) used by the HARMONIE limited area Numerical Weather Prediction system (Bengtsson et al., 2017). SIMPA model, developed and run by CEDEX, has been calibrated and used for the evaluation of natural water resources in Spain, within the framework of the hydrological planning process carried out by the Spanish D.G. Water. An observational grid of meteorological parameters is routinely used to force SIMPA for this evaluation task. HARMONIE is used at AEMET for short range forecasting and global climate models dynamical downscaling. The pilot river basin (Miño Alto) in North-Western Spain has been selected by stakeholders and is not affected upstream by anthropogenic river flow. In this work SEAS5 downscaled seasonal forecasts of meteorological parameters are used to force the simulations by the two hydrological models over the filling reservoir season.

Water inflow accumulated over November to March by SIMPA and SURFEX is compared against that produced by the currently used empirical forecasting system S-ClimWare, based on snow coverage-NAO teleconnection (Voces et al., 2016). Water inflow derived from the lower resolution SEAS5 runoff (based on the TESSEL land surface model, Balsamo et al., 2009) has also been included in the comparison. This pilot experiment has allowed us to test the added value produced by a 
downscaling based on hydrological models, and the effect of Best NAO weighting of the forecasts by the different ensemble members. A comprehensive verification of deterministic and probabilistic seasonal forecasts of water inflow to the Belesar reservoir (in terms of accuracy, sharpness, reliability, resolution and discrimination) has been performed to evaluate separately both factors.

Although climatology differs from one location to another, the methodology applied in this climate service for the Belesar reservoir may be compared to others experienced in Mediterranean areas. Unlike Grillakis et al. (2018) in the Crete Island, where the same hydrological model is driven with forecasts produced by two distinct SFSs, in our exercise the impact of two different hydrological models forced with the same meteorological fields is verified. An alternative approach has been used by Contreras et al. (2018) to produce seasonal forecasts of water inflow for a river hydropower system in Southern Spain. These authors use statistical regionalization techniques to downscale the streamflow produced by the low resolution E-HYPE hydrological model driven by the ECMWF System-4 meteorological forcing. They assess their reliability and sharpness, finding an improvement with respect to current operational forecasts based on historical data. On the other hand, Marcos et al. (2017), have explored seasonal predictability of water resources in North-Eastern Spain using a deterministic statistical approach.

In this prototype, three systems have been set up to produce November to March accumulated water inflow for Belesar water reservoir: SIMPA and SURFEX hydrological models, and the S-ClimWaRe empirical system.

The SIMPA hydrological model has been developed by CEDEX (Estrela and Quintas 1996, CEDEX, 2020). It is a distributed model with a monthly time step, which simulates the process of transformation of precipitation into runoff in a natural regime, considering the storage of water in soil and aquifers, in addition to the snowpack from which snow melt occurs. In this work, the hydrological cycle in the Belesar reservoir basin has been simulated using SIMPA on a $500 \mathrm{~m}$ resolution grid. A detailed revision of the previous parameter values has been carried out for this basin and its sub-basins. To this end, the series of observed water inputs that have been used have been analysed and the information of the modelled groundwater units has been updated. Consequently, the subsoil modelling parameters -maximum infiltration capacity and aquifer recession coefficient- have been slightly recalibrated.

The SURFEX land surface model (Masson et al., 2013)- run at subdaily time step on a $5 \mathrm{~km}$ resolution grid- has been used as an alternative hydrological model in this prototype. Whereas SIMPA is a relatively simple model hydrologically tuned at basin scale, SURFEX is a more physically based model with different hydrological options but not locally tuned.

SURFEX is a state-of-the-art surface model composed of various physical models for natural land surface, urbanized areas, lakes and oceans. It has its own initialisation procedures and can be used in standalone mode or coupled to an atmospheric model (more information can be obtained in the SURFEX web site https://www.umr-cnrm.fr/surfex/). Along this work SURFEX has been used in stand-alone mode. Several configurations related to soil humidity and hydrology were tested and the best agreement with observations was obtained with the 3-layer Force-Restore (3-L) option and the runoff scheme of Dümenil and Todini (DT92), (Dümenil and Todini, 1992) with a characteristic parameter of the basin ' $b$ ' equal to 0.88 (uniform prescribed value of subgrid runoff coefficient parameter XUNIF_RUNOFFB $=0.88$ in SURFEX).

SIMPA and SURFEX were initially run driven by precipitation and temperatures from the AEMET observational grid at $5 \mathrm{~km}$ resolution and bi-linearly interpolated fields from ERA-Interim reanalysis (for the rest of needed forcing variables) to obtain a reference simulation over the 1997-2016 hindcast period. Besides, and for SIMPA simulations, precipitation and temperature fields at $5 \mathrm{~km}$ resolution were monthly aggregated before being further bi-linearly interpolated to the $500 \mathrm{~m}$ resolution model grid. Comparison of the reference experiment forced by observations against water inflow observations indicates a good correlation for both SIMPA $\left(\mathrm{R}^{2}=0.7\right)$ and SURFEX $\left(\mathrm{R}^{2}=0.63\right)$, although interannual variability of water inflow simulated by both models is higher than the observed one. Fig. 4 also allows us to see that both simulations are closer between them than to the observations.

Then, both SIMPA and SURFEX hydrological models started their simulations since 1st November until end of March and driven by the SEAS5-D ensemble of downscaled precipitation and temperature seasonal forecasts -applying the corresponding CSTools function - for the whole 1997-2016 hindcast period. The rest of sub-daily meteorological parameters needed to force SURFEX was obtained by bi-linear interpolation of the corresponding SEAS5 ensemble member to the SURFEX grid.

The S-ClimWaRe statistical system was also run over the same hindcast period using the snow advance in October to forecast an ensemble of winter NAO index values. Then, a K-nearest neighbour (K$\mathrm{nn}$ ) method was applied to each member NAO using historical observations of reservoir inflow to create an ensemble of November to March water inflow seasonal forecasts.

Finally, runoff from SEAS5 ensemble members was interpolated to grid points corresponding to the basin collected by Belesar reservoir and scaled-up to generate water inflow.

Water inflow forecasts from ensemble members coming from SIMPA, SURFEX or SEAS5 were then postprocessed in two different ways, giving place to two different experiments based on the same hydrological model. One of them considers equal likelihood for all ensemble members (EQENSM ensemble postprocessing strategy). The second one applies the CSTools Best NAO algorithm for ensemble members' forecasts weighting (WENSM ensemble postprocessing strategy). A hybrid SClimWaRe statistical system is also run. It replaces the ensemble of NAO index forecasts relying only on the snow cover advance in October, by the Best NAO pdf that also includes the NAO forecast information of SEAS5. In this way, it is consistent with WENSM ensemble postprocessing strategy. The set of the experiments carried out and/or assessed for this prototype is presented in Table 2. Ensemble members' forecasts for these 8 experiments have been processed to obtain water inflow anomalies and then probabilities for the three categories of events defined by the upper and lower tercile of the forecasts statistical distribution for every November to March period between 1997 and 2016 (Fig. 1).

\section{Table 2}

Characteristics of the experiments carried out in the prototype to produce seasonal forecasts of water inflow to Belesar reservoir concerning the method used, resolution, meteorological forcings (SEAS5: ECMWF System-5, or SEAS5-D: downscaled SEAS5) and strategy to postprocess the forecasts by the different ensemble members (EQENSM: equiprobable members, or WENSM: members weighted with Best NAO pdf)

\begin{tabular}{|c|c|c|c|}
\hline Experiment & Model (resolution) & $\begin{array}{l}\text { Meteorological } \\
\text { forcings }\end{array}$ & $\begin{array}{l}\text { Ensemble forecasts } \\
\text { postprocessing strategy }\end{array}$ \\
\hline SIMPA-EQ & SIMPA (500 m) & SEAS5-D & EQENSM \\
\hline SIMPA-W & SIMPA (500 m) & SEAS5-D & WENSM \\
\hline SURFEX-EQ & $\begin{array}{l}\text { Offline SURFEX } \\
(5 \mathrm{~km})\end{array}$ & SEAS5-D & EQENSM \\
\hline SURFEX-W & $\begin{array}{l}\text { Offline SURFEX } \\
(5 \mathrm{~km})\end{array}$ & SEAS5-D & WENSM \\
\hline SClimWaRe & $\begin{array}{l}\text { S-ClimWaRe } \\
\text { (local) }\end{array}$ & Not needed & EQENSM \\
\hline $\begin{array}{l}\text { SClimWaRe- } \\
\text { H }\end{array}$ & $\begin{array}{l}\text { Hybrid S- } \\
\text { ClimWaRe (local) }\end{array}$ & Not needed & WENSM \\
\hline SEAS5-EQ & $\begin{array}{l}\text { ECMWF System-5 } \\
\text { TESSEL ( } 35 \mathrm{~km})\end{array}$ & SEAS5 & EQENSM \\
\hline SEAS5-W & $\begin{array}{l}\text { ECMWF System- } 5 \\
\text { TESSEL ( } 35 \mathrm{~km})\end{array}$ & SEAS5 & WENSM \\
\hline
\end{tabular}




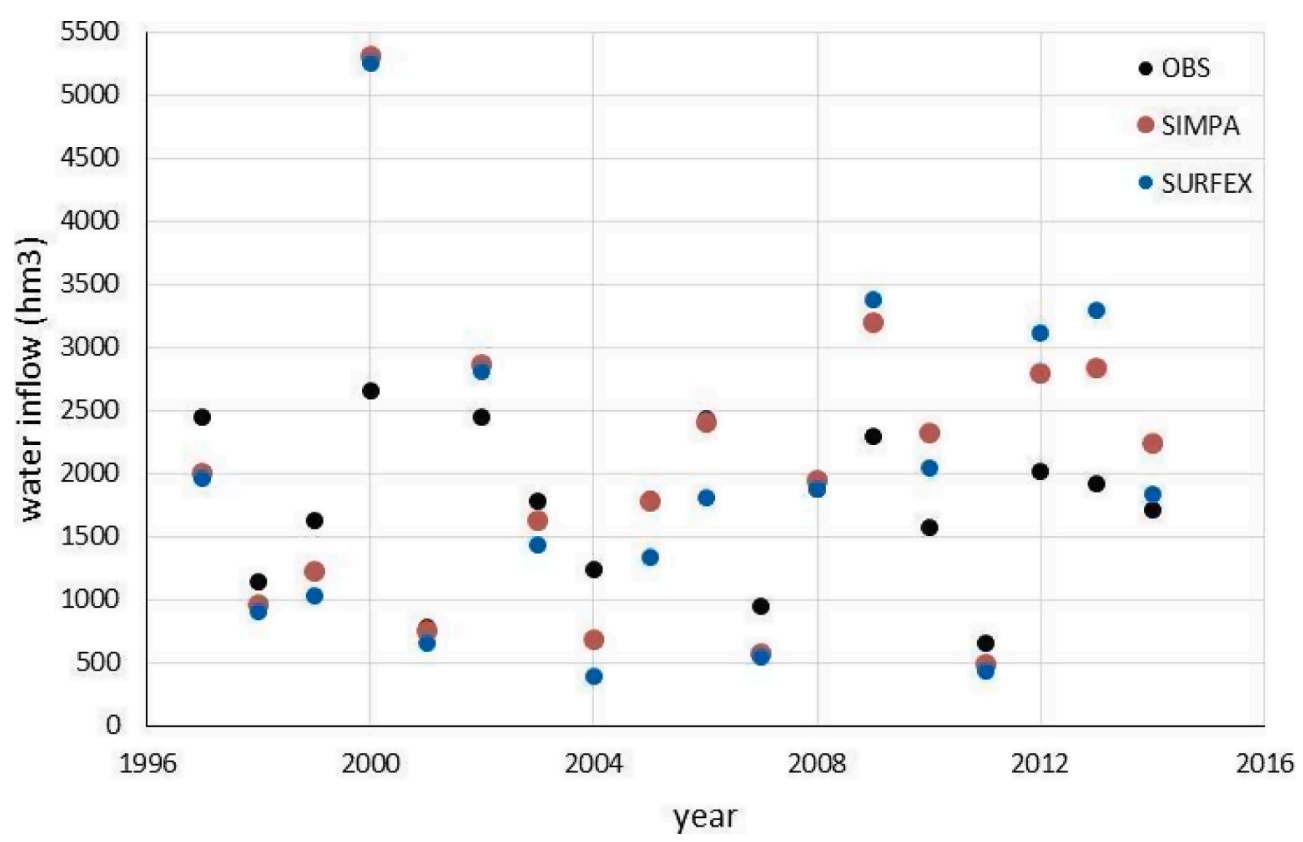

Fig. 1. November to March water inflow to Belesar reservoir simulated by SIMPA (red) and SURFEX (blue) in the reference experiments (driven by the same observational precipitation grid). Observed water inflow at the Belesar reservoir is represented in black.

a)

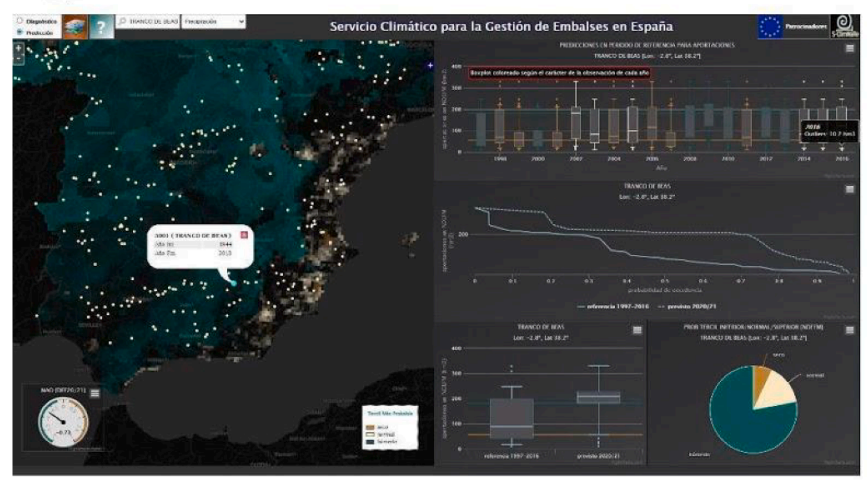

c)

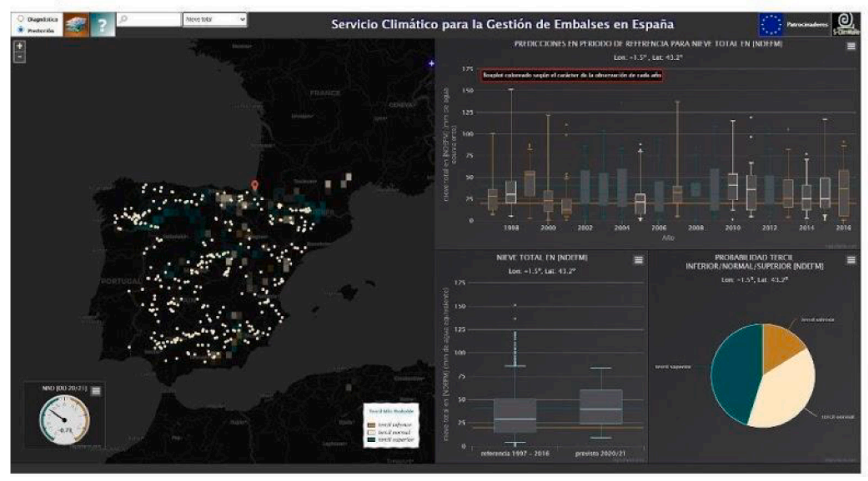

b)

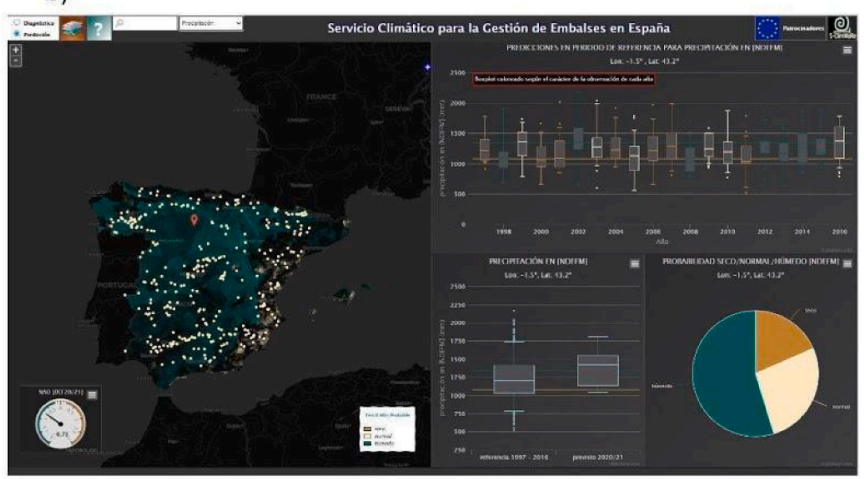

d)

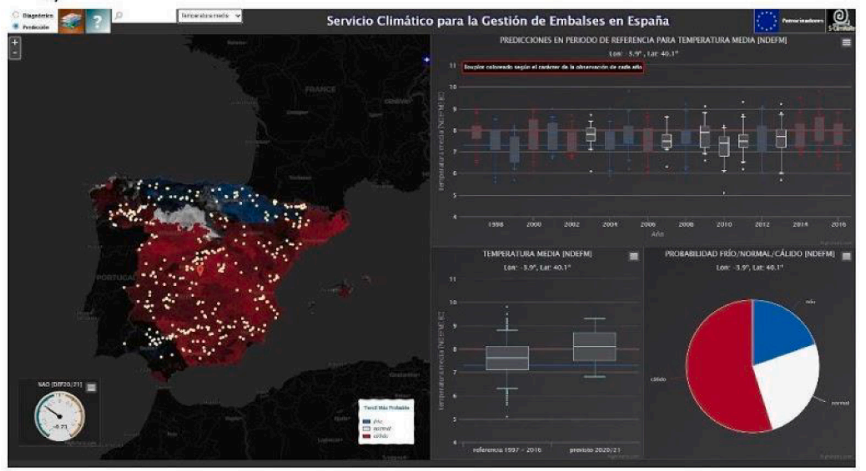

Fig. 2. Overview of the forecasting displaying panels showing seasonal forecasts for November to March of accumulated water inflow (a), accumulated precipitation (b), accumulated snowfall (c) and mean temperature (d).

\section{Results and discussion}

Web tool customization

Several new technical developments have been addressed to get a friendlier S-ClimWaRe viewer. Fig. 2 presents some visualization examples of the full window showing seasonal forecasts for accumulated water inflow, precipitation and snowfall, and mean temperature in this latest version. The chart on the left displays the most likely tercile based category, with transparency levels depending on the forecast skill (measured in terms of the forecast ability to discriminate the different observed categories). The most likely category is only plotted when 


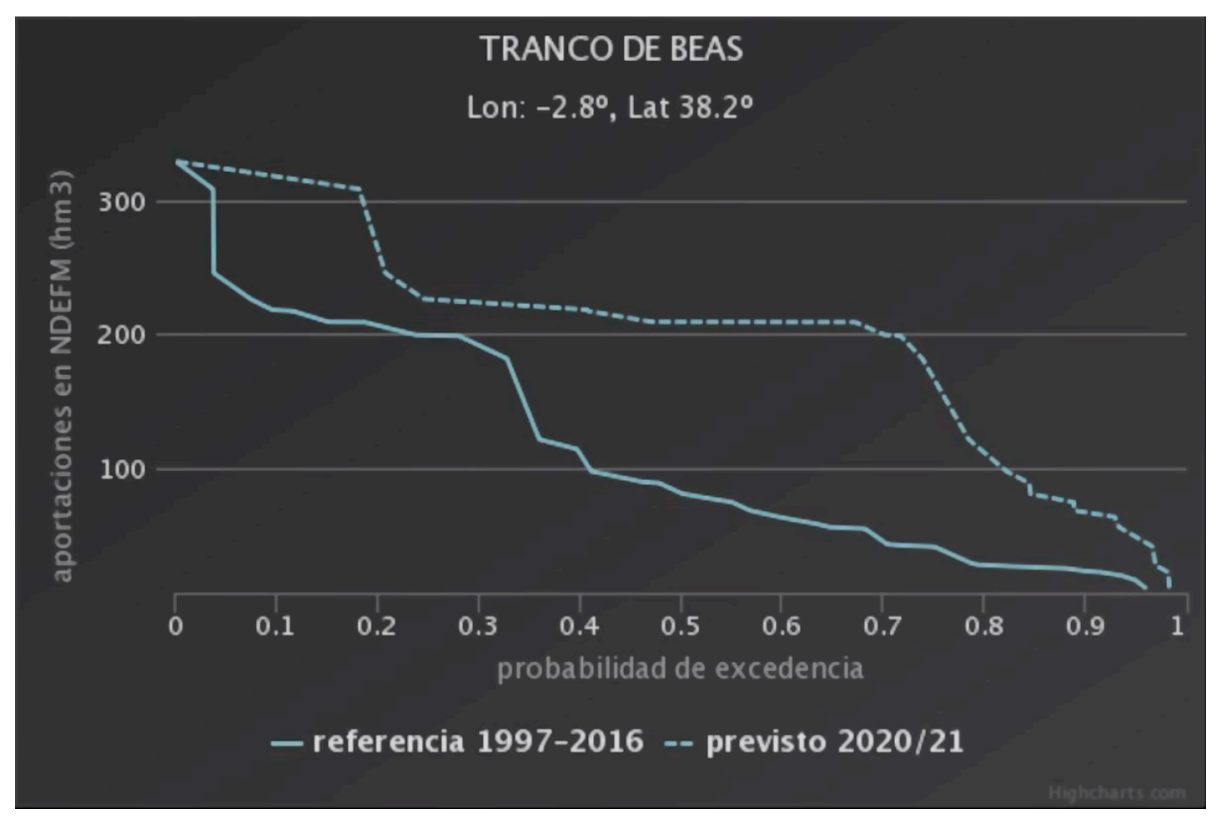

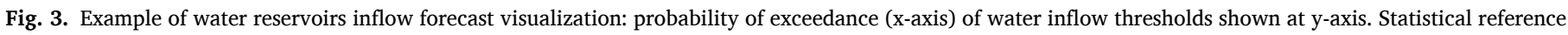
based on observations (full line) and the current seasonal forecast (dashed line) are displayed. Probability data for the selected inflow value are also plotted.

probability exceeds a fixed threshold. The joint revision with stakeholders of the former web viewer version led to the choice of the colours palette used for each variable. A mask is also applied in case of winter accumulated snowfall to not show those pixels where snow occurs rarely. Users have preferred to use box plots instead of histograms to show the forecast uncertainty and the reference statistical distribution at a given grid point. A new graph displaying past years probabilistic forecasts and the observed tercile based category, helps the user to better understand the seasonal forecasts skill at the selected location/reservoir. A new plot shows the probability of exceeding a range of water inflow thresholds at a given water reservoir, displaying both the statistical reference based on observations, and the current seasonal forecast (Fig. 3).

New functionalities have also been agreed and introduced. They refer to the possibility of visualizing each graph using an emerging window, to download the data used in the plot as a csv format file, and to optionally plot snow basin borders based on shapes files provided by D. G. Water. A similar option was already available to plot river basins and subbasins. Finally, logos and a link to the web page of the two European projects that have promoted or partially sponsored the web viewer (EUPORIAS and MEDSCOPE) have been also included, in order users may know in more detail their purposes and achievements.

\section{Assessment of the new seasonal forecasts implemented}

An objective verification against observations has been carried out to assess the skill of the new implemented forecasts. Forecasts for all variables have been obtained for the 20 years hindcast period, between 1997 and 2016. Following observations have been used: i) E-OBS dataset for low resolution SEAS5 forecasts and ii) AEMET $5 \mathrm{~km}$ resolution gridded observations over the Spanish territory for SEAS5-D forecasts. D. G. Water gauge data have been used to verify water inflow forecasts, and ERA5 reanalysis fields have been employed as snow mass proxy observations for snowfall forecasts assessment. Different verification scores have been calculated. Among them, correlation coefficient is selected to represent the accuracy of the deterministic forecast based on the ensemble mean. ROC area has been one of the scores used to explore whether the forecasts capture the tercile based categories of the observed anomalies. It is based on the observed events and measures the ability of the probabilistic forecast to discriminate between the occurrence or not of certain events (e.g. to be below the lower tercile). For skilful probabilistic forecasts ROC area exceeds 0.5 , being the most skilful when it approaches 1 . However the ROC area does not give information about a possible bias in forecasts. The Brier skill score (BSS) reached by the probabilistic forecasts has also been obtained. BSS is based on the forecasts, and provides information about the forecast reliability and resolution. It ranges from -1 to 1 . Positive values of BSS indicate skill of the seasonal forecast against the usage of climatology. The closer BSS is to 1, the better. Sharpness of the probabilistic distribution of forecasts has also been examined. The impact of application of the two applied functions from CSTools is presented hereafter.

\section{Downscaling of precipitation and temperature}

The first function from CSTools applied is intended to downscale precipitation and temperature SEAS5 forecasts. It has a positive impact mainly in regions where the global model already has some skill. Fig. 4 shows the case of the precipitation probabilistic forecasts, calculated considering ensemble members as equiprobable (EQENSM strategy), of the two categories corresponding to a wet and a dry winter, respectively.

Overall, temperature SEAS5-D forecasts show to have more skill and over a wider area than those for precipitation when considering discrimination of a warm winter. In this case, the CSTools function for downscaling temperature forecasts has a clear positive impact on forecasts (see Fig. 5, red/blue coloured pixel indicates a skilful/not skilful probabilistic forecast). However, discrimination of a cold winter is only improved by the regionalization procedure in areas where the global forecasts already have high skill. In general, downscaling highlights features already perceived at lower resolution in global forecasts. Temperature probabilistic forecasts present a sharper probabilistic distribution than those for precipitation (not shown). This fact has been very much welcome by final users.

Accumulated precipitation SEAS5 and SEAS5-D seasonal forecasts for November to March have also been postprocessed considering Best NAO ensemble member weights (WENSM strategy). Fig. 6 shows that there is forecast skill (BSS and ROC area scores) for most of the Spanish geographical domain when this CSTools function is applied.

Application of Best NAO algorithm to total precipitation and snowfall

In order to better understand the effect of the ensemble members weighting procedure on precipitation forecasts, the difference in 

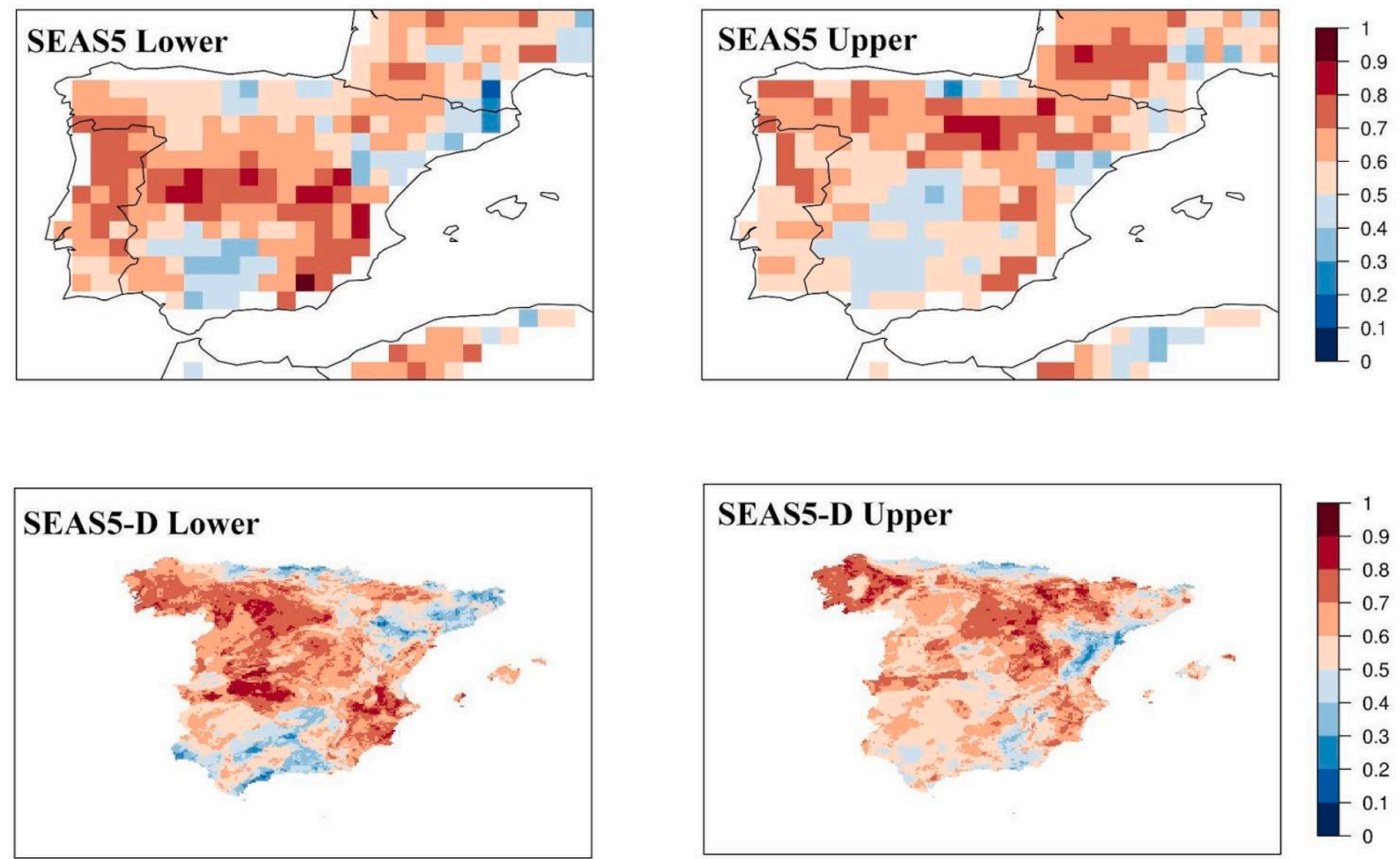

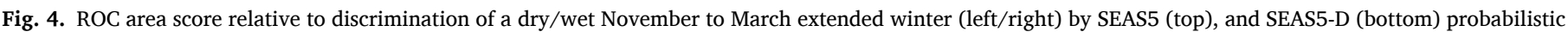

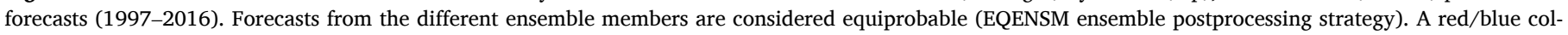
oured pixel indicates a skilful/not skilful forecast.
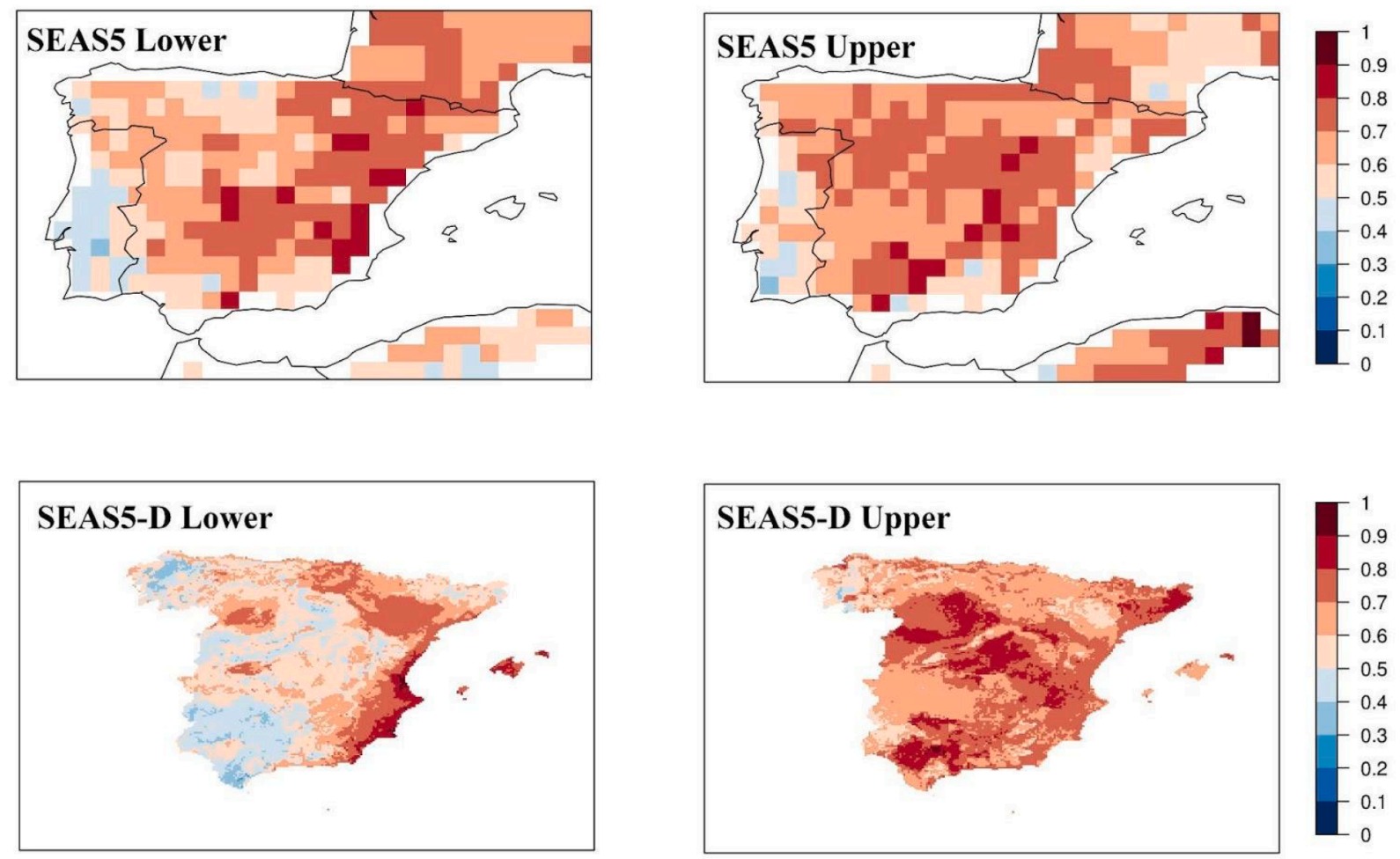

Fig. 5. ROC area score relative to discrimination of a cold/warm winter (left/right) by SEAS5 (top), and SEAS5-D downscaled (bottom) probabilistic forecasts (1997-2016). A red/blue coloured pixel indicates a skilful/not skilful forecast. 

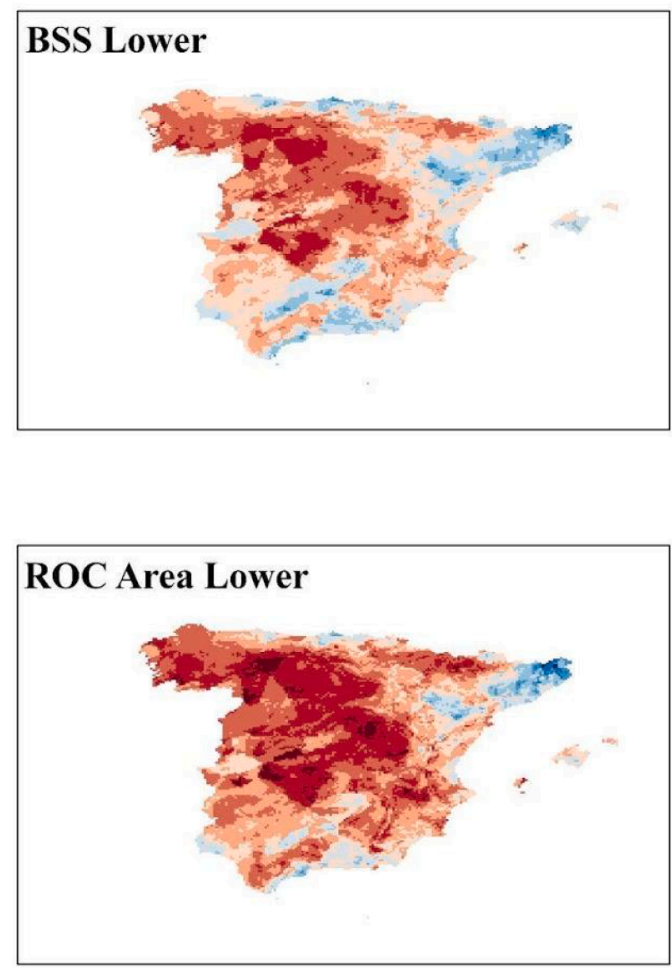
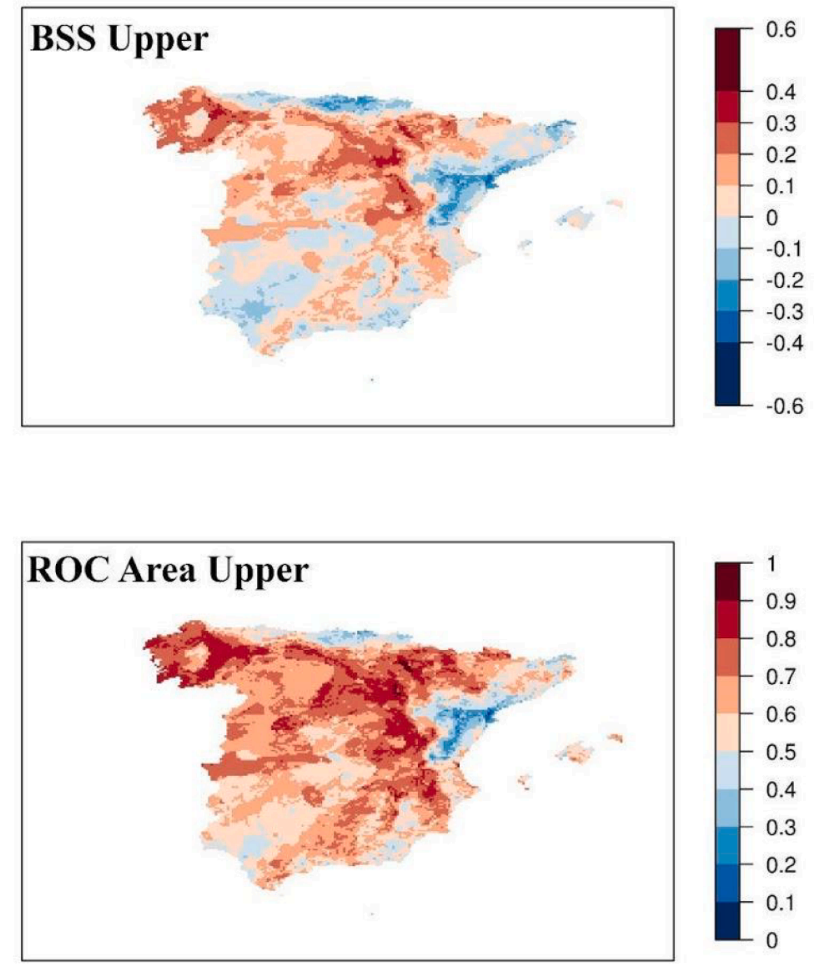

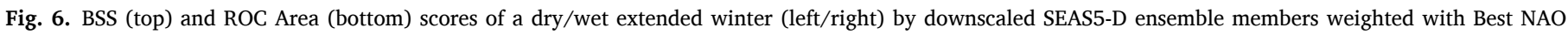
method, WENSM (1997-2016). A red/blue coloured pixel indicates a skilful/not skilful forecast.

verification scores obtained by the seasonal forecasts created with the two ensemble postprocessing strategies applied has been plotted (see Fig. 7). Green/brown shaded areas indicate an improvement/deterioration due to the Best NAO weighting with respect to consider equiprobable members. Green shaded areas dominate in maps for differences in BSS, ROC area and correlation coefficient, indicating the general improvement of the precipitation deterministic and probabilistic forecasts due to ensemble members weighting with Best NAO. Within probabilistic forecasts, the greatest improvement is found for those of the lower tercile of precipitation. Only the Mediterranean coast area shows some areas with a detrimental impact of this ensemble members weighting method.

Evaluation of seasonal forecasts for November to March accumulated snowfall shows that the application of the Best NAO CSTools for weighting SEAS5 ensemble members' forecasts produces a general improvement (Fig. 8).

The benefit of this CSTools function is more noticeable at the Pyrenees area, where the System- 5 direct output has no skill if forecasts by the different ensemble members are considered equiprobable. This figure also shows that there is forecast skill over most of the Spanish mountain ranges where it snows more or less regularly every winter. In any case, the verification results obtained should be regarded with caution because of the limitations of snow mass proxy observations used in this assessment.

\section{Water inflow forecasted by hydrological models}

Fig. 9 shows the verification scores obtained by the different experiments forecasting water inflow to Belesar reservoir.

In general, almost all experiments assessed present skill for the forecasted November to March accumulated water inflow into Belesar. The results obtained show that ensemble members weighting with the Best NAO estimate improves the forecasts in all models: SURFEX, SIMPA and SEAS5 (the most). SIMPA-W and SURFEX-W show the best skill (very similar between both models). The ensemble mean of SIMPA-W forecasts exhibits the highest correlation with observations. In terms of probabilistic forecasts, SURFEX-W obtains the best verification scores (especially for anomalies above the upper tercile). The skill of S-ClimWare empirical model forecasts is very similar to those of SIMPA-EQ and SURFEX-EQ. The S-ClimWaRe-H experiment, making use of the Best NAO forecast estimate, only slightly improves the pure statistical SClimWaRe method for water inflow below the lower tercile. The skill of S-ClimWaRe-H relative to discrimination of anomalies below the lower tercile is very similar to that of SIMPA-W and SURFEX-W. However, forecasts from the purely and the hybrid statistical systems perform worse in terms of BSS score measuring resolution and reliability. Water inflow derived from SEAS5 runoff forecasts performs the worst, although Best NAO ensemble members' weighting improves considerably the skill, according to the scores obtained by SEAS5-W experiment. This finding justifies the downscaling of seasonal forecasts using hydrological models forced by high resolution enhanced meteorological seasonal forecasts, and postprocessed with an appropriate ensemble members' weighting method to better predict the winter NAO.

\section{Discussion}

Although it is demonstrated that both CSTools functions applied improve seasonal precipitation forecasts produced directly by SEAS5, the goal of this new version of S-ClimWaRe viewer was to enhance those implemented originally, coming from the S-ClimWaRe statistical system. Maps in Fig. 10 display the difference in ROC area between the upgraded precipitation forecasts obtained through application of the two MEDSCOPE CSTools functions and those coming from the empirical system originally implemented in the web viewer. Again, shaded areas in green/brown indicate an improvement/deterioration by the upgraded forecasts. It can be seen that impact on forecast skill results to be neutral over wide areas in Central Spain, it is slightly negative over the Southwest part of the Iberian Peninsula (where skill of the statistical SClimWaRe was already very high), and it is mostly positive along the Mediterranean coast, the Ebro valley and the Cantabrian area in Northern Spain. Forecasts from the empirical S-ClimWaRe system have 

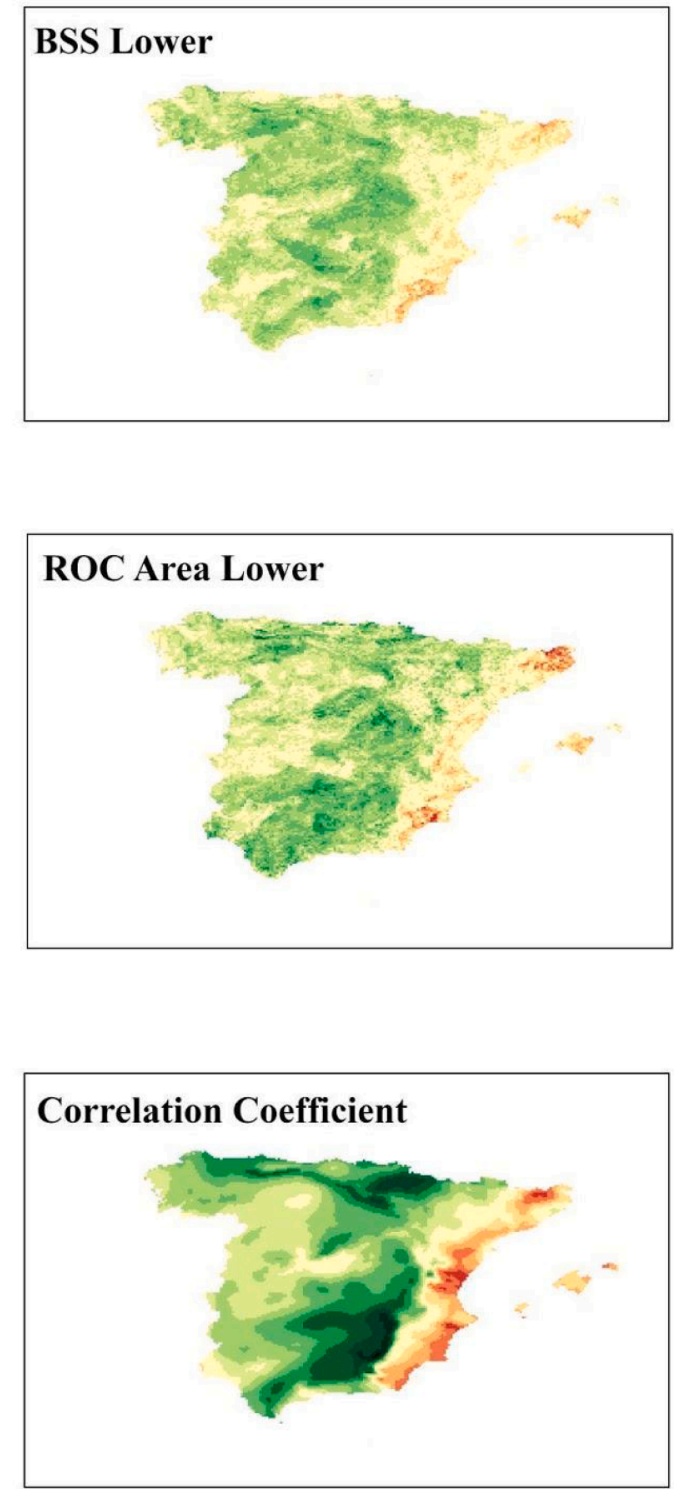
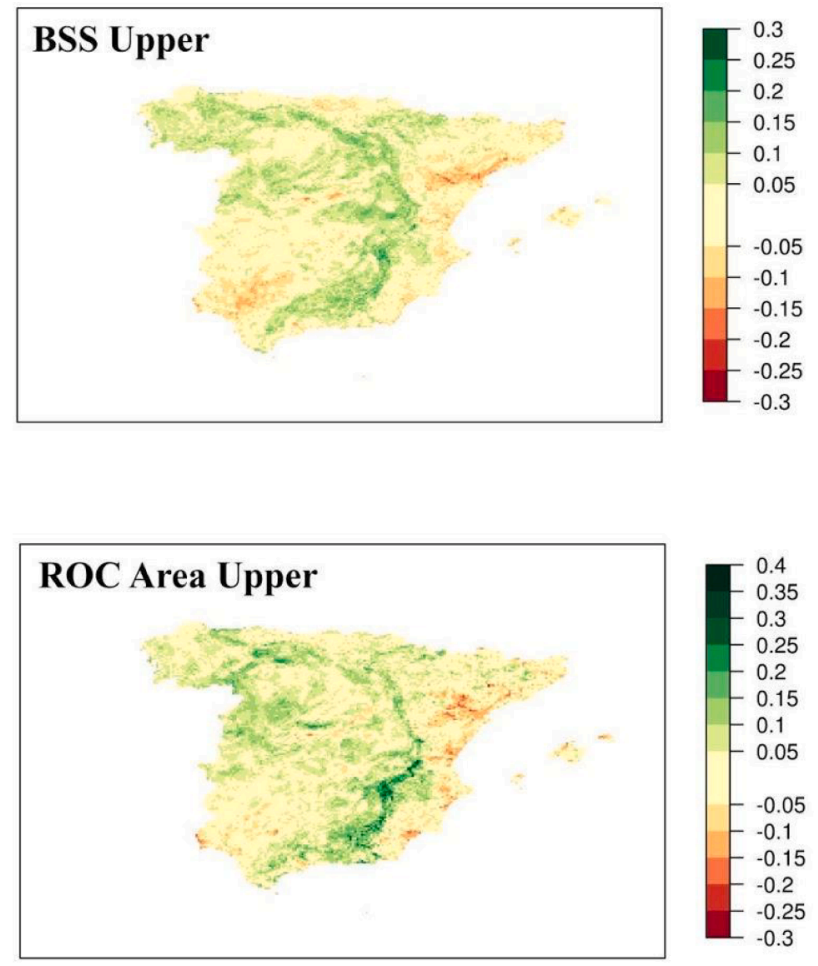

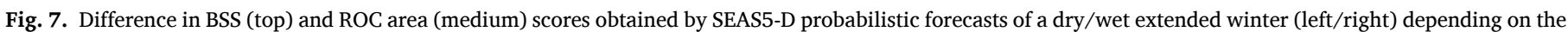

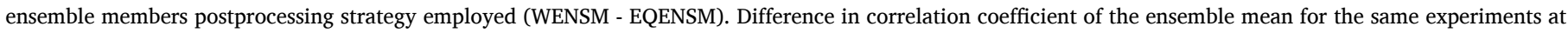

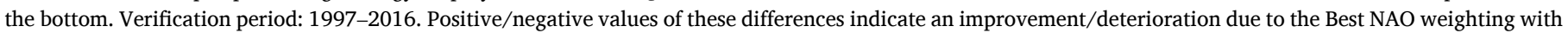
respect to consider equiprobable members.

no skill in these areas where the new developments have produced an improvement, because they are not so directly impacted by the NAO pattern. Along the Mediterranean coast winter precipitation is not correlated with NAO, however SEAS5 forecasts present some skill there. The new forecasts are taking into account this feature. So, it can be said that the overall impact of these MEDSCOPE developments has been positive for precipitation forecasts, extending the regions where seasonal forecasts are skilful. This is more noticeable for discrimination of a wet winter. The total area where there is forecast skill in this upper tercile has increased to $5 \%$, reaching $88 \%$ of the Spanish territory $(90 \%$ in case of seasonal forecasts discriminating a dry winter).

Forecasts of water inflow produced by the original S-ClimWaRe statistical system are based on a reliable forecast of the winter NAO. This is also the case of the hybrid S-ClimWaRe-H method. In the upgraded version of S-ClimWaRe viewer, seasonal forecasts of accumulated precipitation are consistent with those of water inflow in areas largely influenced by this climate driver. In these regions, seasonal forecasts of water inflow are also skilful in the new web tool (not shown). However, $\mathrm{S}$-ClimWaRe-H method is not able to better predict water inflow at many reservoirs located in green shaded areas in Fig. 10, where precipitation forecasts skill has improved due to the usage of SEAS5 forecasts but that are not directly influenced by the NAO pattern. An improvement of water inflow forecasts skill there might be obtained through the usage of impact models based on hydrological models driven by SEAS5-D forecasts (as it is demonstrated in the prototype tested at the Belesar reservoir), or using alternative statistical methods relying on skilful precipitation forecasts.

Besides their quality and skill, sharpness is another key property of probabilistic forecasts valuable for supporting decision making by end users. The ensemble spread of experiments that only differ on the members weighting method seems to be very similar (not shown). When comparing all different experiments between them, SIMPA and then SClimWaRe present the smallest spread (being SIMPA slightly smaller). SURFEX seems to have less sharpness, and SEAS5 the least. Taking also into account all verification scores obtained for probabilistic forecasts and for the ensemble mean, SIMPA forecasts would be possibly the most valuable suite for end users.

There are other advantages associated with the new seasonal 

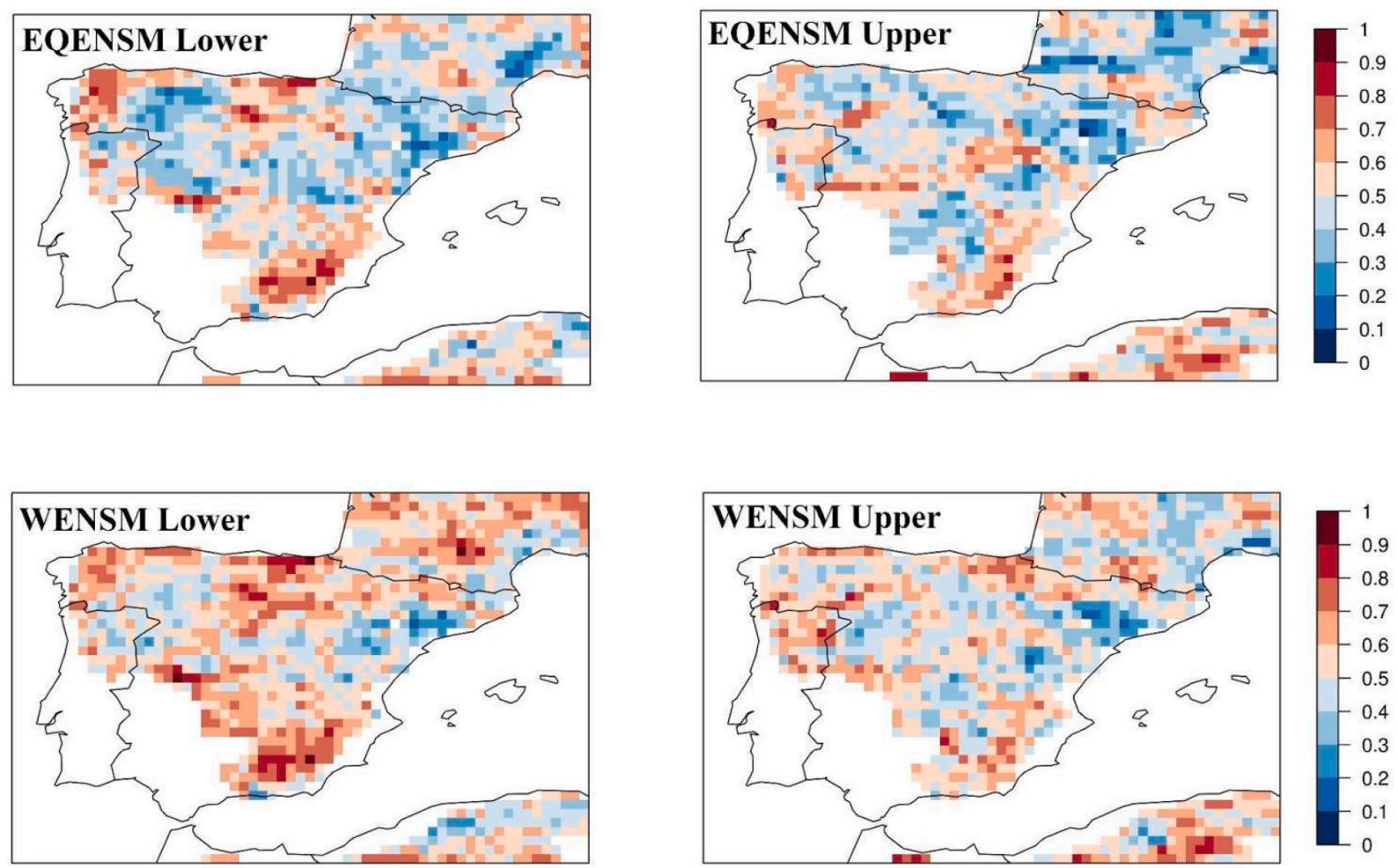

Fig. 8. ROC Area score for accumulated snowfall forecasts by SEAS5: equiprobable members (EQENSM ensemble postprocessing strategy, top), and Best NAO ensemble members weighting (WENSM ensemble postprocessing strategy, bottom). Snowfall below/above lower/upper tercile is shown at left/right. The assessment is based on ERA5 reanalysis (1997-2016).

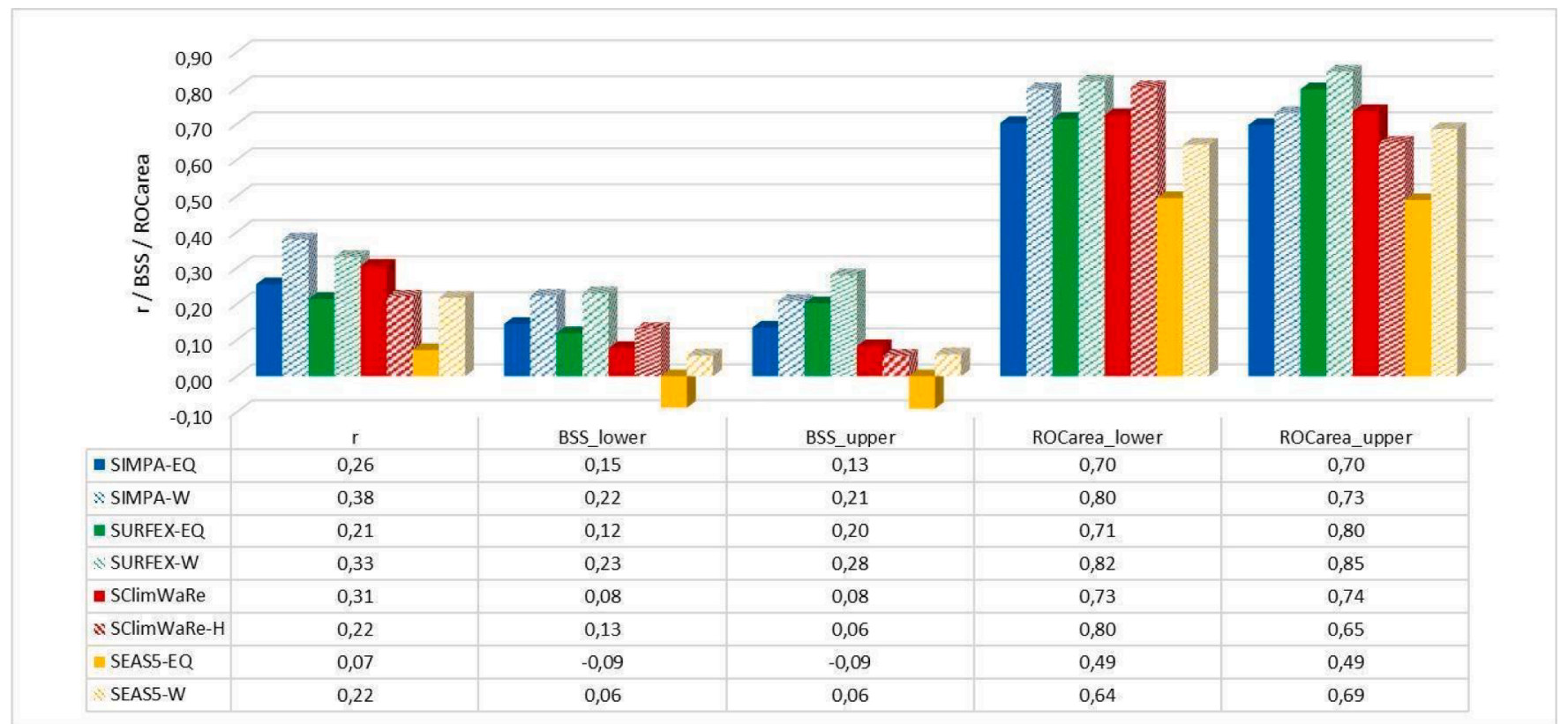

Fig. 9. Verification scores obtained by the seasonal forecasts of November to March water inflow to Belesar reservoir of the different experiments: correlation coefficient (r) of the ensemble mean, and BSS and ROC area for probabilistic forecasts to be below/above the lower/upper tercile. See Table 2 for a description of the experiments.

forecasts created using these two MEDSCOPE CSTools functions. They are based on an ensemble of forecasts produced by a GCM. So, forecasts for more variables are available (as e.g. snowfall, soil moisture, temperature...), and the higher temporal resolution of the model output allows to use them to drive different application models to provide the parameter required by the different customers (as it has been tested in this prototype with two hydrological models delivering seasonal forecasts of water reservoir inflow). On the other hand, the Best NAO CSTools function takes intrinsically into account the NAO index forecast accuracy of the different information sources. As the skill of climate models to predict this relevant climate driver improves, they will have a greater influence on the optimal estimation of the NAO index used for 

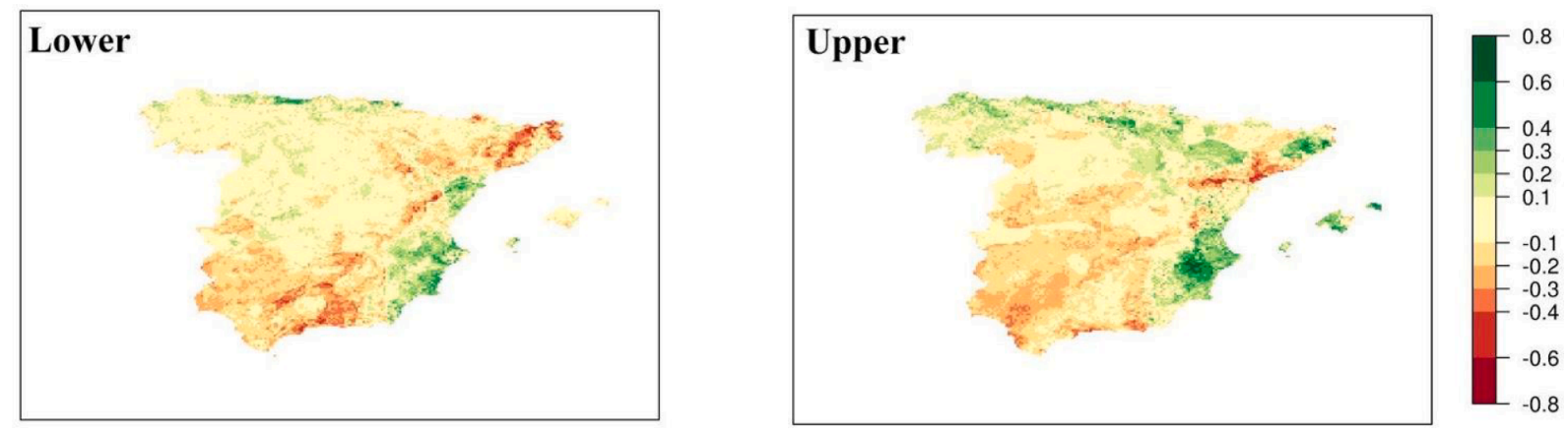

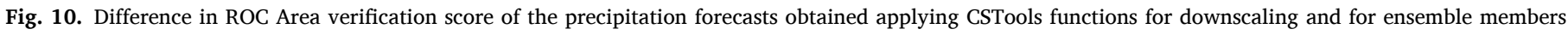

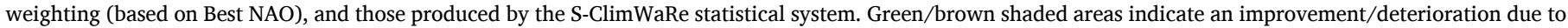

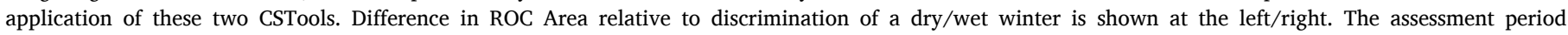
is $1997-2016$.

weighting ensemble member predictions. It should be also mentioned that the improvement of water inflow and precipitation forecasts produced by the statistical system is limited by both the length of series of observations used and by its own simplicity, relying on the influence of the NAO pattern in the whole area. On the contrary, GCMs implicitly take into account not only a single external forcing (as it is the case of snow cover advance) but all the sources of NAO predictability, on top of other climate drivers that may have an impact on climate variability in the region. So, their usage guarantees a progressive increase of forecast skill in the future.

\section{Conclusions}

The evolution of the S-ClimWaRe climate service, addressed to support decision-making concerning water reservoirs in Spain, has been presented. This climate service is fully user driven. A strong commitment of stakeholders has allowed a continuous improvement of this tool, meeting user's requirements and incorporating scientific progress.

Several free-access datasets of observations, reanalysis, and seasonal forecasts are processed in different and novel ways and feed the upgraded version of this web tool. Some technical enhancements requested by customers have been introduced, and new seasonal predictions are obtained through application of two MEDSCOPE postprocessing tools to SEAS5 forecasts aiming at providing higher spatial resolution and an enhanced skill. The latter is achieved through an improved prediction of the winter NAO, the relevant climate driver for this area and season. This method, which combines different NAO skilful forecasts, takes into account their accuracy and allows the addition of more information sources. In this way, a future enhancement of GCMs forecasts will be straightforwardly incorporated into the S-ClimWaRe climate service. The upgraded web tool extends the area with precipitation forecast skill, and provides additional forecasts for accumulated snowfall and temperature. Water inflow forecasts are consistent with the predicted NAO index and are generated by a hybrid statistical system. They are also skilful in areas influenced by this climate driver. In regions not directly affected by the NAO pattern, a revision of the impact model employed to obtain seasonal predictions of water inflow seems to be needed.

A prototype based on two different hydrological models to produce the seasonal forecasts of water inflow has been tested over a pilot reservoir. These models are forced by the enhanced precipitation and temperature forecasts introduced in the web viewer. The assessment of this downscaling procedure shows promising results with respect to the existing seasonal forecasts based on a statistical approach. Although this methodology needs further testing spanning the rest of Spanish water reservoirs, it is considered really useful by stakeholders. Progressive broadening of the scope of the pilot experiment to other reservoirs with different uses would be highly desirable. In the long term, including the seasonal forecasts produced by high resolution hydrological models among the products to be provided regularly to the end user, e.g. by replacing those available in the S-ClimWaRe viewer coming from the statistical system, is recommended (whenever reservoirs are managed under a natural regime and are not influenced by anthropogenic effects). With respect to a further evolution of this tool, end users have also required monthly disaggregated seasonal forecasts and to have them also for the rest of seasons. All these requirements will be further analysed within the cyclic interaction maintained between all actors of this climate service. A new enhancement would also incorporate other improvements concerning e.g. the extension of the hindcast period, or the improvement of forecast quality due to the combination of additional skilful seasonal predictions, as e.g. those available at the Copernicus Climate Data Store coming from the UKMO GloSea5 SFS, once they have been calibrated as suggested by Stringer et al. (2020).

The enhanced S-ClimWaRe viewer has become operational once the 2020-2021 extended winter forecasts have been uploaded, in order it may be used by stakeholders. Free access to this tool has been made through both AEMET and D.G. Water websites. The new version of SClimWaRe web viewer is being subjectively assessed by D.G. Water and most of the Spanish River Basin Authorities. They are also starting to develop new methods oriented to use these forecasts in practical decision making concerning water reservoirs management.

\section{CRediT authorship contribution statement}

E. Sánchez-García: Methodology, Software, Validation, Formal analysis, Investigation, Writing - original draft, Visualization. I. Abia: Methodology, Software, Validation, Formal analysis, Resources, Visualization. M. Domínguez: Software, Formal analysis, Investigation. J. Voces: Software, Formal analysis, Investigation. J.C. Sánchez: Software, Formal analysis, Investigation. B. Navascués: Conceptualization, Methodology, Validation, Investigation, Writing - review \& editing, Supervision, Project administration. E. Rodríguez-Camino: Conceptualization, Investigation, Writing - review \& editing. M.N. Garrido: Validation, Investigation. M.C. García: Validation. F. Pastor: Validation. M. Dimas: Software, Formal analysis, Methodology, Investigation. L. Barranco: Software, Formal analysis, Methodology, Investigation. C. Ruiz Del Portal: Validation.

\section{Declaration of Competing Interest}

The authors declare that they have no known competing financial interests or personal relationships that could have appeared to influence the work reported in this paper. 


\section{Acknowledgements}

Samuel Viana, Esteban Rodríguez, Asunción Pastor, Federico Franco and Alfonso Hernánz have provided essential support to different tasks of the latest upgrade carried out in the S-ClimWaRe web tool. The SClimWaRe viewer presented in this paper contains Copernicus Climate Change Service information [2020], in particular ERA5 reanalysis data and SEAS5 modified forecasts. ECMWF implements the Copernicus Climate Change Service and the Copernicus Atmosphere Monitoring Service on behalf of the European Commission. ERA-Interim reanalysis data used for this work has been generated by ECMWF. IMS Daily Northern Hemisphere Snow and Ice Analysis at $24 \mathrm{~km}$ resolution by the U.S. National Ice Center, and time series of monthly mean NAO index provided by the U.S. National Oceanic and Atmospheric Administration, are also employed.

The research leading to these results has received funding from the MEDSCOPE project co-funded by the European Commission as part of ERA4CS, an ERA-NET initiated by JPI Climate, grant agreement 690462.

\section{References}

Amblar-Francés, et al., 2020. High resolution climate change projections for the Pyrenees region. Adv. Sci. Res. 17, 191-208. https://doi.org/10.5194/asr-17-191-2020.

Arnal, L., et al., 2018. Skilful seasonal forecasts of streamflow over Europe? Hydrol. Earth Syst. Sci. 22, 2057-2072.

Balsamo, G., et al., 2009. A revised Hydrology for the ECMWF model: verification from field site to terrestrial water storage and impact in the integrated forecast system. J. Hydrometeorol. 10, 623-643.

Bengtsson, L., et al., 2017. The Harmonie-arome model configuration in the ALADINHIRLAM NWP system. Mon. Weather Rev. 145, 1919-1935. https://doi.org/ 10.1175/MWR-D-16-0417.1.

Brown, C., et al., 2010. Managing Climate Risk in Water Supply Systems, IRI Tecnical Report 10-15. International Research Institute for Climate and Society, Palisades, New York. http://iri.columbia.edu/publications/id=1048. (Accessed 24 December 2021).

Buontempo, C., et al., 2018. What have we learnt from EUPORIAS climate service prototypes? Clim. Serv. 9, 21-32. https://doi.org/10.1016/j.cliser.2017.06.003.

CEDEX, 2020. Evaluación de Recursos Hídricos en régimen natural en España (1940/412017/18). Informe técnico para la DGA. Madrid, enero 2020. https://www.miteco. gob.es/es/agua/temas/evaluacion-de-los-recursos-hidricos/evaluacion-recur sos-hidricos-regimen-natural/.

Cohen, J., Jones, J., 2011. A new index for more accurate winter predictions. Geophys. Res. Lett. 38, L21701. https://doi.org/10.1029/2011GL049626.

Contreras, E. et al., 2018. Seasonal Climate Forecast Skill Assessment for the Management of Water Resources in a Run of River Hydropower System in the Poqueira River (Southern Spain). Water 2020, 12(8), 2119, https://doi.org/ $10.3390 / \mathrm{w} 12082119$.

Dee, D.P., et al., 2011. The ERA-interim reanalysis: configuration and performance of the data assimilation system Q.J.R. Meteorol. Soc. 137, 553-597. https://doi.org/ 10.1002/qj.828.

Díez, E. et al., 2011. Downscaling ECMWF seasonal precipitation forecasts in Europe using the RCA model. Tellus A: Dynamic Meteorology and Oceanography, 63:4, 757762.https://doi.org/10.1111/j.1600-0870.2011.00523.x.

Doblas-Reyes, F., 2012. Seasonal prediction over Europe. ECMWF Seminar on Predictability in the European and Atlantic regions.

Dümenil, L., Todini, E., 1992. A rainfall-runoff scheme for use in the Hamburg climate model. Advanced.

Estrela, T. and Quintas, L, 1996. A distributed hydrological model for water resources assessment in large basins. RIVERTECH 96. 1st International Conference on New/ Emerging Concepts for Rivers. IWRA. Sep. 22-26, 1996. Chicago. EE.UU.

Grillakis, M., Koutroulis, A., Tsanis, I., 2018. Improving seasonal forecasts for basin scale hydrological applications. Water 10 (11), 1593. https://doi.org/10.3390/ w10111593.

Guihan, R. et al., 2014. Value of Forecasts in Reservoir Operations Management. Conference: World Environmental and Water Resources Congress, 1041-1049, http://dx.doi.org/10.1061/9780784413548.104.

Helfrich, S.R., McNamara, D., Ramsay, B.H., Baldwin, T., Kasheta, T., 2007. Enhancements to, and forthcoming developments in the Interactive Multisensor Snow and Ice Mapping System (IMS). Hydrol. Process. 21, 1576-1586. https://doi. org/10.1002/hyp.6720.

Hernanz, A., García-Valero, J.A., Domínguez, M., Ramos-Calzado, P., PastorSaavedra, M.A., Rodríguez-Camino, E., 2021. Evaluation of statistical downscaling methods for climate change projections over Spain: present conditions with perfect predictors. Int. J. Climatol. https://doi.org/10.1002/joc.7271.
Hersbach, H. et al., 2019. ERA5 monthly averaged data on single levels from 1979 to present. Copernicus Climate Change Service (C3S) Climate Data Store (CDS).

Hewitt, et al., 2012. The launch of the global framework for climate services. Nat. Clim. Change 2, 831-832. https://doi.org/10.1038/nclimate1745.

Klein-Tank, et al., 2002. Daily dataset of $20^{\text {th }}$-century surface air temperature and precipitation series for the European climate assessment. Int. J. Climatol. 22, 1441-1453.

Long, Y., et al., 2019. Seasonal inflow forecasts using gridded precipitation and soil moisture information: implications for reservoir operation. Water Resour. Manage. 33, 3743-3757. https://doi.org/10.1007/s11269-019-02330-8.

Marcos, R., et al., 2017. Seasonal predictability of water resources in a Mediterranean freshwater reservoir and assessment of its utility for end-users. Sci. Total Environ. 575, 681-691. htpps://doi.org/10.1016/j.scitotenv.2016.09.080.

Masson, V., et al., 2003. A global database of land surface parameters at 1-km resolution in meteorological and climate models. J. Clim. 16 (9), 1261-1282. https://doi.org/ 10.1175/1520-0442(2003)16\%3C1261:AGDOLS\%3E2.0.CO;2.

Masson, V., et al., 2013. The SURFEXv7.2 land and ocean surface platform for coupled or offline simulation of earth surface variables and fluxes. Geosci. Model Dev. 6, 929-960.

MIMAM, 2000 Libro Blanco del Agua. Ministerio para la Transición Ecológica y Reto Demográfico. ISBN: 9788483201282, https://www.miteco.gob.es/es/agua/temas/ planificacion-hidrologica/libro-blanco-del-agua/.

MITERD, 2021. Sistema Nacional de cartografía de Zonas Inundables - Inventario de Presas SNCZI-IPE, https://sig.mapama.gob.es/WebServices/clientews/snczi/default. aspx ? origen $=8 \&$ nombre $=$ PRESA_ESTADISTICA_1 \& claves $=$ \&valores.

Olsson, J., et al., 2016. Technical note: initial assessment of a multi-method approach to spring-flood forecasting in Sweden. Hydrol. Earth Syst. Sci. 20, 659-667. https:// doi.org/10.5194/hess-20-659-2016.

Peral, C., Navascués, B., Ramos, P., 2017. Serie de precipitación diaria en rejilla con fines climáticos. Nota Técnica n ${ }^{\circ}$ 24, AEMET. http://hdl.handle.net/20.500.11765/7573.

Pérez-Zanón, N. et al, 2021. CSTools: Assessing Skill of Climate Forecasts on Seasonal-toDecadal Timescales. R package version 4.0.1., https://CRAN.R-project. org/package=CSTools, http://doi.org/10.5281/zenodo.5549474.

Petisco de Lara, S.E., 2008a. Método de regionalización de precipitación basado en análogos. Explicación y Validación. AEMET Nota Técnica 3A, Área de Evaluación y Modelización del Cambio Climático. AEMET, Spain.

Petisco de Lara, S.E., 2008b. Método de regionalización de temperatura basado en análogos. Explicación y Validación. AEMET Nota Técnica 3B, Área de Evaluación y Modelización del Cambio Climático. AEMET, Spain.

Pouget, L. et al., 2015. Use of seasonal climate predictions in the water sector-preliminary results from the EUPORIAS project. Chapter of the book: Drought: Research and Science-Policy Interfacing, ISBN: 9780429226380, https:// doi.org/10.1201/b18077.

Riddle, E.E., Butler, A.H., Furtado, J.C., et al., 2013. CFSv2 ensemble prediction of the wintertime Arctic Oscillation. Clim. Dyn. 41, 1099-1116. https://doi.org/10.1007/ s00382-013-1850-5.

Rodríguez-Puebla, C., et al., 1998. Spatial and temporal patterns of annual precipitation variability over the Iberian Peninsula. Int. J. Climatol. 18, 299-316. https://doi.org/ 10.1002/(SICI)1097-0088(19980315)18:3<299::AID-JOC247>3.0.CO;2-L.

Sánchez-García, E., Voces-Aboy, J., Rodríguez-Camino, E., 2014. Calibration and combination of seasonal forecast over Southern Europe. AEMET. https://doi.org/ 10.31978/281-14-014-X.

Sánchez-García, E., Voces-Aboy, J., Navascués, B., Rodríguez-Camino, E., 2019. Regionally improved seasonal forecast of precipitation through Best estimation of winter NAO. Adv. Sci. Res. 16, 165-174. https://doi.org/10.5195/asr-16-165-2019.

Scaife, A., et al., 2014. Skilful long-range prediction of European and North American winters. Geophys. Res. Lett. 41, 2514-2519. https://doi.org/10.1002/ 2014GL059637.

Stockdale, T.N., Molteni, F., Ferranti, L., 2015. Atmospheric initial conditions and the predictability of the Arctic Oscillation. Geophys. Res. Lett. 42, 1173-1179. https:// doi.org/10.1002/2014GL062681.

Stringer, N., Knight, J., Thornton, H., 2020. Improving meteorological seasonal forecasts for hydrological modeling in european winter. J. Appl. Meteorol. Clim. 59 (2), 317-332. https://doi.org/10.1175/JAMC-D-19-0094.1.

Turner, S., et al., 2017. Complex relationship between seasonal streamflow forecast skill and value in reservoir operations. Hydrol. Earth Syst. Sci. 21, 4841-4859. https:// doi.org/10.5194/hess-21-4841-2017.

Viel, C., et al., 2016. How seasonal forecast could help a decision maker: an example of climate service for water resource management. Adv. Sci. Res. 13, 51-55. https:// doi.org/10.5194/asr-13-51-2016.

Visser, J., 2017. Evaluation of Seasonal Inflow Forecasting to Support Multipurpose Reservoir Management: A case study for the Upper Maule River Basin, Chile. TVVR17/5016 VVRM01 20171, Division of Water Resources Engineering, Lup Student Papers, http://lup.lub.lu.se/student-papers/record/8918892.

Voces, J., et al., 2019. Web based decision support toolbox for Spanish reservoirs. Adv. Sci. Res. 16, 157-163. https://doi.org/10.5194/asr-16-157-2019.

Voces, J., Sanchez-Garcia, E., Navascués, B., Franco, F., Rodriguez-Camino, E., 2016. Sistema estadístico de predicción estacional para la gestión de los embalses en España, Nota Técnica. n 21, AEMET. https://doi.org/10.31978/281-16-003-1. 